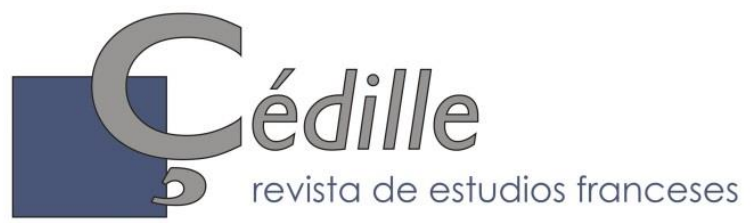

ISSN: 1699-4949

$\mathrm{n}^{0} 18$ (otoño de 2020)

Monografías 11

Epistemocrítica: análisis literario y saber científico

Amelia Gamoneda Lanza \& Francisco González Fernández, editores científicos

\title{
Traductoras en el gozne del cambio de paradigma cientí- fico
}

\author{
Lourdes PÉREZ GonZÁLEZ \\ Universidad de Oviedo \\ lourdes@uniovi.es \\ ORCID: 0000-0002-2165-6098
}

\section{Resumen}

Entre los siglos XVII y XVIII se produce una revolución científica en todos los ámbitos del conocimiento, personificada por la historia con algunos nombres destacados. Pero detrás, al lado, a lo lejos, muchos otros nombres -de mujer también- participaron en este proceso realizando distintas tareas, entre ellas la traducción (sobre todo al/ del francés, lengua de mayor proyección entonces). Viajaremos por el cambio de paradigma en física y química y pondremos el foco, en esa zona oscura pero necesaria del gozne que articula esa larga transformación, sobre algunas mujeres traductoras, científicas autodidactas, cuya tarea indispensable para la transmisión y consolidación del conocimiento, fue velada o desdibujada.

Palabras clave: Traducción, Física, Química, Paradigma, Francés, Mujeres.

\section{Résumé}

Les $\mathrm{XVII}{ }^{\mathrm{e}}$ et $\mathrm{XVIII}{ }^{\mathrm{e}}$ siècles ont été le cadre d'une révolution scientifique majeure dont les principaux acteurs sont reconnus par l'histoire. Or, derrière ces grands noms, à leur côté ou au loin, d'autres noms - de femmes aussi - ont participé à ce processus par la réalisation de tâches diverses dont, notamment, la traduction (en et du français surtout, la langue qui s'imposait à l'époque). Nous suivrons ce changement de paradigme en physique et en chimie et mettrons en lumière - dans cette zone obscure mais nécessaire qui constitue la charnière de cette longue transformation - ces traductrices, scientifiques autodidactes, dont le travail, indispensable pour la transmission et la consolidation des connaissances, a été voilé ou négligé.

Mots clé : Traduction, Physique, Chimie, Paradigme, Français, Femmes

\begin{abstract}
Between 17th and 18th centuries we witnessed a scientific revolution in all the branches of knowledge, whose most remarkable names history keeps record of. But behind, on the sidelines, in the distance, many other names - of women too - participated in this process of carrying out different tasks, including translation (especially to / from French, language of greater projection then). We will examine the paradigm shift in phys-
\end{abstract}

* Artículo recibido el 25/02/2020, aceptado el 25/10/2020. 
ics and chemistry, focusing on this dark zone of the hinge which is needed to explain how this long transformation took place, putting the focus on some female translators, selftaught scientists, whose indispensable role for transmission, dissemination and consolidation of knowledge was veiled or blurred.

Keywords: Translation, Physics, Chemistry, Paradigm, French, Women.

L'humanité est mâle et l'homme définit la femme non en soi mais relativement à lui ; elle n'est pas considérée comme un être autonome.

16)

Simone de Beauvoir (1949: I, 15-

\section{La/s lengua/s y las revoluciones científicas}

A principios del siglo XVIII, cuando empieza la vida de una de las traductoras objeto de este trabajo, Gabrielle Émilie Le Tonnelier de Breteuil, marquesa de Châtelet (1706-1749), el latín era la lengua indiscutible en la que se hacía y debía expresarse la ciencia y, por tanto, la herramienta con la que los eruditos podían comunicarse entre ellos, independientemente de cuál fuera su lengua materna. El latín era la lingua franca para los (pocos) científicos. De hecho, desde el siglo V al siglo XI, prácticamente todos los documentos están escritos en latín; era la lengua de la Iglesia, las escuelas y los monasterios, aunque en los siglos X y XI aparecen ya testimonios escritos de equivalencias en lengua vulgar al margen de los textos latinos, que se fueron desarrollando en los siglos XII y XIII, consolidándose las lenguas vernáculas en el XIV. A partir del siglo XV-XVI, la literatura ya se produce en las lenguas vernáculas, pero la ciencia se estudia en latín (textos originales o traducidos del griego o del árabe) y, en menor medida en griego, y se escribe también en latín. Los autores pioneros en la utilización de lenguas vernáculas en textos científicos fueron Alberto Durero, en alemán, en 1525, con un tratado sobre medición con compás y regla (Underweysung der Messung, mit dem Zirckel und Richtscheyt, in Linien Ebnen und gantzen Corporen); Galileo Galilei, en italiano, en 1623, con un debate sobre el movimiento del universo en torno al sol (Dialogo sopra i due massimi sistemi del mondo Tolemaico, e Coperniciano); René Descartes, en francés, en 1637, con una de las obras que inaugura el pensamiento moderno y que destaca el valor de las matemáticas en la creación de la nueva ciencia (Discours de la méthode pour bien conduire sa raison, et chercher la vérité dans les sciences); o Robert Boyle, en inglés, en 1661, con un texto que planteó que la materia está formada por átomos y sus combinaciones cuyo movimiento es la base de todo fenómeno (The sceptical chymist).

Pero no todas estas lenguas tenían el mismo peso ni la misma influencia, había variaciones en función de quien ejerciera mayor poder político y económico: en los siglos XV y XVI el peso era del castellano, en el XVII y el XVIII del 
francés y, ya a partir del XIX el inglés. El italiano, sin haber sido la lengua de un gran imperio fue, sin embargo, la lengua de las cortes europeas occidentales en el siglo XV y XVI, ya que era la lengua de la Iglesia de Roma, una institución que extendió los brazos de su poder a todas las naciones católicas (Cáceres, 2000: 48).

El francés medieval, que se hablaba desde el siglo IX hasta el XIV en la mitad norte del territorio francés actual y por la nobleza normanda en sus territorios (Sicilia, islas británicas...), se había hecho oficial en el primer tercio del siglo XVI, en el territorio galo y en la corte de Bruselas y empezó a definirse como un idioma estable y reconocido a nivel internacional en 1634, cuando el cardenal Richelieu creó la Académie Française ${ }^{1}$, para estandarizar la lengua oral y escrita, así que en la segunda mitad del siglo XVII, tras la creación de la Académie des sciences en 1666 según el proyecto de Colbert, primer ministro de Luis XI, se hallaba ya completamente extendida alcanzando una proyección mundial, rivalizando con el latín en el ámbito científico.

De modo que a partir del siglo XVII el contexto lingüístico había evolucionado: las lenguas vernáculas estaban consolidadas, pero las élites (sobre todo las científicas) conocían y utilizaban el latín. Y en este contexto empieza a cristalizar una transformación importante de las ciencias. Es lo que Kuhn denomina revolución científica, que significa un cambio de paradigma para sustituir, una vez cuestionado y refutado, lo que estaba funcionando como evidencia científica hasta ese momento.

En La estructura de las revoluciones científicas (1962), Kuhn aborda la ciencia como una actividad concreta que en cada época histórica presenta peculiaridades y características propias y que se desarrolla siguiendo determinadas fases caracterizadas por distintos paradigmas o realizaciones científicas universalmente reconocidas. «Un paradigma es lo que los miembros de una comunidad científica comparten y, a la inversa, una comunidad científica consiste en hombres que comparten un paradigma» (Kuhn, 1971: 271). Cuando el paradigma no es capaz de resolver todos los problemas (también llamados anomalías o enigmas), y estos persisten a lo largo de los años o de los siglos, el paradigma en conjunto comienza a ponerse en cuestión, con vistas a resolver la o las cuestiones más problemáticas (Sánchez-Cerezo, 2003) y a sustituir el paradigma vigente por un nuevo paradigma (como sucedió con la visión copernicana del mundo, que derrocó a la concepción aristotélica, o con la teoría de la relatividad de Albert Einstein, que sustituyó a la visión newtoniana de la realidad), comenzando un nuevo ciclo y un nuevo proceso de ciencia normal, que no suele ser fácil y armonioso ni unánimemente compartido por toda la comunidad científica; de hecho: «El surgimiento de un paradigma afecta a la estructura del grupo que practica en ese campo [...] Pero hay siempre hombres que se aferran a alguna de las viejas opiniones» (Kuhn, 1971: 45-46).

\footnotetext{
${ }^{1}$ No fue la primera, la Accademia della Crusca se fundó en Florencia en 1583, pero sí la de mayor influencia (la Real Academia española se fundó en 1713 a imitación de la francesa).
} 
A principios del siglo XVIII, las anomalías que se habían ido acumulando a lo largo de varios siglos eran suficientes para que el paradigma vigente no solo en las ciencias más experimentales (física y química), sino también en las metodologías y procedimientos, así como en los medios y recursos para la divulgación de conocimientos (lenguas vehiculares, canales de comunicación, soportes de transmisión, traducciones...) culminara un camino largo y dificultoso hacia los nuevos paradigmas.

\section{Cambio de paradigma en física}

¿Cómo se produjo este cambio de paradigma? Recordemos que el concepto que imperaba en física hasta el siglo XVI era el de geocentrismo, que colocaba en el centro a la Tierra (aunque ya en el s. III a. C., Aristarco de Samos, después de estudiar el tamaño y la distancia del sol y determinar que el sol era mucho más grande que la tierra, concluyó que la tierra y los planetas giraban alrededor del sol -heliocentrismo-), basado en la teoría geocéntrica de Aristóteles, desarrollada siglos más tarde por Ptolomeo (Crombie, 1978, 1980).

Ptolomeo (siglos I-II d. C.) es el autor del tratado astronómico Almagesto (el gran tratado) preservado, como muchos tratados científicos griegos clásicos, en un manuscrito árabe, posteriormente disponible en el s. XII en la traducción al latín de Gerardo de Cremona -que se trasladó de Italia a Toledo para traducir ese texto-, versión que pasó a la tradición científica europea. Su modelo del universo era el aristotélico: la Tierra estaría inmóvil ocupando el centro del universo, pero el Sol, la Luna, los planetas y las estrellas, en vez de girar alrededor de la tierra a una distancia fija, girarían desplazándose en un pequeño círculo, llamado «epiciclo».

Este conocimiento, al que se fueron incorporando dudas e incertidumbres, generadas por la cada vez mayor sofisticación y precisión de aparatos de observar y medir -el astrolabio (ya descrito por Ptolomeo e Hipatia de Alejandría), la esfera armilar, el reloj astronómico, el equatorium, el nocturlabio...-, no pudo cristalizar hasta el renacimiento, cuando destacan los tres grandes nombres que personalizaron el inicio del cambio de paradigma: Copérnico, Kepler, Galileo y abrieron la puerta a que, finalmente, Newton formulara las leyes de la física gravitacional, consolidándose el cambio de paradigma (Hawking, 2006; Crombie, 1980; Stenger, 1991).

El astrónomo polaco Copérnico (1473-1543) tras observar el cielo nocturno durante más de 30 años desde la torre de la catedral, demostró matemáticamente en De revolutionibus orbium coelestium, publicado el mismo año de su muerte (1543), que la Tierra giraba alrededor del Sol, que la Tierra rotaba completamente sobre sí misma cada 24 horas y que la Tierra daba una vuelta completa al Sol en ciclos de un año, estableciendo un hito, el llamado giro copernicano, que iba a abrir la puerta al cambio de paradigma científico. El astrónomo y matemático alemán Kepler (1571-1630), partiendo de que el Sol era el centro del sistema, descubrió que los cuerpos celestes se movían describiendo elipses -desmontando definitivamente el complejo mecanismo de epiciclos y deferentes de Ptolomeo- y 
sintetizó y describió estos movimientos en tres leyes, sin poder dar consistencia matemática a su teoría, ya que no tenía explicación para esos movimientos, pero había dado un paso más (había aportado una anomalía más a la crisis) en la sustitución del modelo aristotélico. El astrónomo, matemático e ingeniero italiano Galileo Galilei (1564-1642) investigó los problemas que suscitaba el descubrimiento de Copérnico: ¿por qué si la tierra gira sobre su eje los objetos permanecen en su superficie? ¿Cómo puede girar la tierra alrededor del sol sin que nada la impulse? Y experimentó ${ }^{2}$ tirando objetos de distinto tamaño y peso desde la torre inclinada de Pisa ${ }^{3}$, observando que los cuerpos caían al mismo tiempo, independientemente de su masa, tamaño y forma, y que no caían con velocidad constante, como creía Aristóteles, sino que iban acelerándose- pero sin poder explicar la fuerza que los atraía a la superficie de la tierra.

De modo que nos encontramos con nuevas constataciones sobre el movimiento de los astros, pero no generalmente aceptadas, y menos por la iglesia; recordemos que en 1633 la Inquisición romana había condenado a Galileo por afirmar la movilidad de la tierra, y que él decidió retractarse ${ }^{4}$ a cambio de un arresto domiciliario hasta su muerte ${ }^{5}$.

Sobre el campo abonado por estos antecedentes, el científico inglés (físico, matemático, filósofo, alquimista...) Newton (1642-1727) publicó, en 1687 y en latín, Philosophiae Naturalis Principia Mathematica donde formuló en términos matemáticos sus tres leyes de la mecánica o del movimiento y la ley de la gravitación universal, proponiendo una nueva visión de la mecánica, con consecuencias en los campos del movimiento, de las fuerzas y de las formas de los planetas.

Podría pensarse que esta teoría (Galindo, 2012), que resolvía tantas dudas y anomalías, sería rápidamente aceptada, pero no fue así y mucho menos en Francia donde, para el movimiento de los planetas, triunfaba la explicación del filósofo, físico y matemático Descartes (1596-1650), expuesta en Principia Philosophiae, publicada en 1664, que partiendo de la premisa de que Dios existe, explica el mundo como una gran máquina cuyo primer movimiento, que continúa por inercia, en cantidad finita, constante e indestructible, fue un impulso de Dios, aunque, para evitar problemas con la iglesia, que no parecía encajar bien el con-

\footnotetext{
${ }^{2}$ De hecho, sistematizó el método experimental para hacer ciencia. Primero: convertir en datos las observaciones realizadas (transformar en números lo que se observa). Segundo: formular una hipótesis que intente explicar lo observado y deducir las posibles implicaciones (método hipotéticodeductivo). Finalmente: confirmar o refutar la hipótesis planteada tras la experimentación.

${ }^{3}$ Aunque parece que el experimento desde la torre de Pisa no fue real (pero, si non è vero, è ben trovato), sí lo fue el que realizó deslizando pesos sobre planos inclinados con diferentes grados de inclinación.

${ }^{4}$ «[...] Io Galileo Galilei sodetto ho abiurato, giurato, promesso e mi sono obligato come sopra; et in fede del vero, di mia propria mano ho sottoscritta la presente cedola di mia abiuratione et recitatala di parola in parola, in Roma, nel convento della Minerva, questo dì 22 giugno 1633. Io Galileo Galilei ho abiurato come di sopra, mano propria. (Abiura di Galileo Galilei)» (Lux in Arcana Archivo Secreto Vaticano. Museo capitolino. Roma. Febrero-septiembre de 2012).

${ }^{5}$ Peor suerte había corrido el napolitano Giordano Bruno, quemado vivo en 1600 por «herético, impenitente, pertinaz, obstinado» (Prieto, 2017: 127).
} 
cepto de movimiento, indicó que no existía el movimiento ni el reposo en sí mismos: «El movimiento y el reposo sólo son dos diversas formas del cuerpo en que se dan» (Descartes, 1995: 89) y, para mayor seguridad, se instaló en Holanda entre 1629 y 1649, donde la Iglesia era más tolerante que en Francia; aun así, cuando se enteró de la sentencia ${ }^{6}$ del Santo Oficio a Galileo, renunció a la publicación de Le Monde / Traité du monde et de la lumière, donde expone el movimiento de la tierra, obra que se publicará en 1664, después de su muerte.

Como ya hemos apuntado, la difusión y asimilación de la nueva física fue lenta, también en Francia, no sólo por razones ideológicas, religiosas y nacionales (recordemos que la Académie des sciences de France y la universidad de la Sorbona son cartesianas) sino por las dificultades inherentes a los lenguajes empleados (el lenguaje matemático, fundamentalmente geométrico, y el latín), de ahí la importancia de los textos de divulgación de la teoría científica y de las traducciones que permitieron el trasvase de conocimientos y la comunicación entre científicos.

La primera obra de divulgación de las teorías de Newton en Francia es la del astrónomo y matemático francés Maupertius ${ }^{7}$, que había ingresado en la Académie des sciences en 1723 y que en 1728 visita Londres, donde descubre las ideas de Newton, siendo su primer gran defensor en Francia, y que publica en 1732 Discours sur la figure des astres... avec une Exposition abbrégée des systèmes de M. Descartes et de M. Newton, par M. de Maupertuis, donde se posiciona a favor de Newton en general y, en concreto, en la controversia sobre la forma de la tierra -según Newton tenía forma de elipsoide de revolución (achatada por los polos) - frente a Cassini (cartesiano y francés) -para quien estaba estirada por los polos (achatada por el ecuador) ${ }^{8}$.

La segunda obra de divulgación es de Voltaire, ampliamente conocido y estudiado como autor teatral y poeta, como filósofo ilustrado inspirador de la revolución francesa y como partícipe en la elaboración de la magna obra Encyclopédie ou Dictionnaire raisonné des sciences, des arts et des métiers ${ }^{9}$.

\footnotetext{
${ }^{6}$ En Roma se publica el 2 de julio, en Florencia el 12 de agosto, en Alemania a finales de agosto, en Bélgica en septiembre, en Francia no llega a publicarse.

${ }^{7}$ En aquellos momentos, uno de los pocos franceses (por no decir el único) newtoniano.

${ }^{8}$ La Académie des sciences organiza dos expediciones para medir la longitud de un arco polar y de un arco ecuatorial y poder determinar la forma de la Tierra. La primera en 1735 al Virreinato de Perú, compuesta por Louis Godin, Pierre Bouguer y Charles Marie de la Condomine, además de los científicos españoles Jorge Juan y Santacilia y Antonio de Ulloa. La segunda a Laponia en 1736, compuesta por Maupertuis, Clairaut y Celsius. En los años cuarenta se difundieron los resultados de estas expediciones, quedando demostrado el achatamiento por los polos (como defendían los newtonianos) y no el achatamiento por el ecuador (como defendían los cartesianos).

${ }^{9} 45$ artículos (solo o en colaboración): élégance, éloquence, esprit, finesse, français imagination...
} 
De Voltaire se conocen sus polémicas con la Iglesia, su planteamiento anticlerical (aunque deísta ${ }^{10}$ ), su posicionamiento por un estado laico con división de poderes, su defensa de las libertades.

De Voltaire también se conoce su facilidad para buscarse problemas con sus sátiras y críticas ${ }^{11}$ y su afán viajero y cosmopolita ${ }^{12}$, a veces por exilio o autoexilio, o por deseo de conocer.

Menos se conoce su inmensa fortuna, amasada al calor de operaciones financieras más o menos «especulativas» ${ }^{13}$.

Y menos aún su faceta científica.

Voltaire estaba en Inglaterra en 1727 (donde se había exiliado tras su segundo paso por la Bastilla), el mismo año de la muerte de Newton, al que no llegó a conocer, pero a cuyo funeral asistió. Al regresar a Francia en 1731, escribió sus Lettres Anglaises o Lettres Philosophiques ${ }^{14}$ (se publican en 1734), en las que critica duramente las instituciones francesas comparándolas con las inglesas, que considera modélicas y civilizadas (frente al fanatismo dogmático del cristianismo en Francia opone la libertad de pensamiento y la tolerancia religiosa en Inglaterra; frente al despotismo francés opone la libertad ideológica inglesa y frente al cartesianismo imperante opone la filosofía newtoniana), lo que lleva al Gobierno francés a condenar y secuestrar la obra y a emitir una orden de arresto contra él. Voltaire había iniciado una relación en 1733 con Gabrielle Émilie Le Tonnelier de Breteuil, marquesa de Châtelet y se refugia con ella en Cirey, en una propiedad del marqués de Châtelet, marido de Émilie, que Voltaire se ocupó de restaurar (ya disponía de una gran fortuna), dotándola con un gabinete para realizar experimentos de física y una gran biblioteca. Allí pasaron los siguientes diez años dedicados a la investigación científica.

Fruto de este periodo son dos obras, una de Voltaire y otra de Émilie.

Describiremos brevemente la de Voltaire que, convencido de que tenía que divulgar la obra de Newton (Aboites, 2001), escribió y publicó en Amsterdan, en 1738, Éléments de la philosophie de Newton, obra que le abrió las puertas de gran

\footnotetext{
${ }^{10}$ Nada podía explicarse sin la existencia de un «Ser Supremo». La ciencia podía explicar un fenómeno como el de la gravitación, pero estaba limitada para explicar las causas de dicho fenómeno (esto correspondía a Dios).

${ }^{11}$ Fue encarcelado en la Bastilla en 1717 (un año) por burlarse del regente de Luis XIV, Felipe de Orleans y su hija. Y de nuevo en 1726 (unos meses) por un incidente con un miembro de la familia de Rohan.

12 Estancias en Londres (1726-28), Cirey (1735-44), Paris (1745-47), Luneville (1748), Berlín (1750-54), Ginebra (I 755-57) y Ferney (1758-78). Frecuentes visitas a Amsterdam, Bruselas, Basilea.

13 Aprovechando algunos errores de diseño de la primera lotería francesa (negocio en que se asoció con su amigo matemático La Condomine), haciendo negocios con los suministros del ejército o facilitando préstamos a la aristocracia.

${ }^{14} 25$ cartas sobre religión, artes, política, filosofía, ciencia (las cartas XIV-XVII son las que abordan cuestiones científicas).
} 
de parte de las academias científicas europeas ${ }^{15}$ y le cerró las de Académie des sciences de France (creada en 1666) y la de la Universidad de la Sorbona, profundamente cartesianas ${ }^{16}$.

El libro consta de tres partes: la primera de nueve capítulos dedicada al análisis de cuestiones metafísicas, la segunda, de trece capítulos, dedicada a exponer la óptica de Newton y la tercera, de catorce capítulos, dedicada a exponer la mecánica newtoniana. Está dedicado a Madame de Châtelet, a quien define como mejor conocedora que él de la obra de Newton:

Madame,

Lorsque je mis pour la première fois votre nom respectable à la tête de ces Éléments de philosophie, je m'instruisais avec vous. Mais vous avez pris depuis un vol que je ne peux plus suivre. Je me trouve à présent dans le cas d'un grammairien qui aurait présenté un essai de rhétorique ou à Démosthène ou à Cicéron. J'offre de simples Éléments à celle qui a pénétré toutes les profondeurs de la géométrie transcendante, et qui seule parmi nous a traduit et commenté le grand Newton. [...] (Voltaire, 1879: 402) ${ }^{17}$.

Pero esta gran obra de divulgación newtoniana no tuvo grandes repercusiones; es más, la Encyclopédie ni la menciona en la entrada redactada por d'Alembert Newtonianisme ${ }^{18}$, donde, por el contrario, sí aparece la Marquesa de Châtelet.

No deja de sorprender que esta obra haya tenido tan poco eco, teniendo en cuenta que en aquel momento el debate newtoniano estaba en plena efervescencia y el cambio de paradigma en física era ya una realidad.

\section{Madame de Châtelet en el gozne del cambio de paradigma}

Estamos a las puertas de la Ilustración, cuyo objetivo sería «disipar las tinieblas de la ignorancia mediante las luces del conocimiento y la razón», para lo que se necesitaba difundir hallazgos, descubrimientos, ideas, promover debates, divulgar el conocimiento a toda la humanidad; la traducción era, pues, una tarea fundamental porque la lengua que unificaba a las élites científicas, el latín, era una lengua excluyente, y porque el debate internacional era cada vez más urgente y

\footnotetext{
${ }^{15}$ Royal Society de Londres, Royal Society de Edimburgo, Accademia Etrusca di Cotorna, Academia Florentina, Academia Prusiana de las Ciencias, Academia de ciencias de Rusia.

${ }^{16}$ Sí ocupó, en 1746, la silla 33 de la Académie française.

${ }^{17}$ Esta Épître dédicatoire, sin fechar en la edición de 1748, figura en la edición de 1756 y posteriores.

18 «[...] Quelques auteurs ont tenté de rendre la philosophie newtonienne plus facile à entendre, en mettant à part ce qu'il y avoit de plus sublime dans les recherches mathématiques, \& y substituant des raisonnemens plus simples, ou des expériences [...] On doit joindre à ces ouvrages celui de $\mathbf{M}$. Maclaurin, qui a pour titre, Exposition des découvertes du chevalier Newton, traduite en françois depuis quelques années, \& le commentaire que madame la marquise du Chatelet nous a laissé sur les principes de Newton, avec une traduction de ce même ouvrage [...]» (L'Encyclopédie, 1751, t.11 p. 123).
} 
necesario. Y la lengua más extendida era el francés (sin descartar que también, o desde el francés, se tradujera al inglés, italiano, alemán...).

Y la traducción, esa tarea de secundarios y de anónimos, ese conglomerado de muchos y muchas que no suelen ser reconocidos individualmente -como las estrellas de la vía láctea- ${ }^{19}$, fue una pieza fundamental del gozne ${ }^{20}$ que articuló el cambio de paradigma.

Gozne que contiene la paradoja de formar el límite y disolverlo, justamente lo que necesita una revolución científica: cerrar sin dejar de abrir, abrir sin cerrar del todo.

En este gozne encontramos la tarea de traductora de Gabrielle Émilie Le Tonnelier de Breteuil, marquesa de Châtelet, nacida en París en 1706 y fallecida a los 43 años, después de su cuarto alumbramiento, en 1749.

En 2006 se celebró por primera vez un coloquio dedicado a Madame de Châtelet y dos años más tarde se publicó el libro de actas (Kölving y Coucelle, 2008). Por primera vez se analizó, debatió, contrastó, la figura de esta mujer que hasta entonces (y todavía actualmente) era fundamentalmente conocida como «la amante de Voltaire», a pesar del talento que demostró en los múltiples ámbitos que cultivó: filosofía, lenguas, música, literatura, ciencia.

Nos centraremos en su faceta de traductora -y divulgadora- de ciencia.

Émilie tuvo una esmerada educación, tanto en música, literatura y lenguas -latín, griego, alemán e inglés- ${ }^{21}$ como correspondía a una dama de su posición y también en ciencias -la que se dispensó a sus hermanos- y que profundizó posteriormente con clases de científicos de alto nivel como Maupertius ${ }^{22}$, Clairaut ${ }^{23} \mathrm{o}$ König $^{24}$, todos ellos miembros de la Academia de Ciencias de Francia (Badinter, 1983, 2008).

Cuando acompaña a Voltaire, que se auto-exilia en Cirey para eludir la or-

\footnotetext{
${ }^{19}$ Aunque se dice que ya en el s. IV a. C. Demócrito interpretó aquel haz blanco en el cielo como muchísimas estrellas muy lejanas, no se supo con certeza hasta que, en 1606, Galileo, utilizando un telescopio, confirmó que eran estrellas demasiado tenues como para ser reconocidas individualmente.

${ }^{20}$ El concepto de gozne que queremos utilizar no es un gozne cualquiera, es el que utilizó Marcel Duchamp para una puerta de su apartamento de la calle Larrey 11 (donde vivió entre 1927 y 1942). La puerta, o comunicaba el baño con el estudio o éste último con el dormitorio, de modo que se cerraba y se abría simultáneamente (Naegele, 2007).

${ }^{21}$ Aprovechó sus estancias en Bruselas para aprender flamenco. Estudió italiano para poder comunicarse con el ensayista italiano Algarotti, cuyo libro de divulgación Newtonianismo per le dame, empezó a traducir, tarea que posteriormente abandonó por considerar el libro poco serio.

${ }^{22}$ La introdujo en el conocimiento de la física newtoniana. Mantuvo con él una relación sentimental antes de instalarse con Voltaire en Cirey.

${ }^{23}$ Escribe entre 1734 y 1736, posiblemente para ella, uno de los primeros libros pedagógicos: Éléments de géométrie (publicado en 1741), posteriormente adaptado al sistema decimal y utilizado en el sistema público de enseñanza.

${ }^{24}$ Matemático enviado por Bernouilli a Cirey para que Émilie siguiera profundizando en las matemáticas y quien la introduce en las teorías de Leibniz. Émilie rompe con él cuando pretende usurparle la autoría de Institutions de Physique.
} 
den de arresto que pesa sobre él por la publicación de las Lettres philosophiques, Émilie utiliza su tiempo para escribir sus propios textos científicos: Institutions de Physique ${ }^{25}$ y Dissertation sur la nature et la propagation $d u f e u^{26}$ y para traducir los Principia Mathematica de Newton.

Institutions de Physique, estaba en prensa en 1738, el mismo año en que Voltaire publicaba en Amsterdan Éléments de la philosophie de Newton (en cuya dedicatoria, como ya hemos indicado, había dejado clara la superioridad de Madame de Châtelet: «seule parmi nous a traduit et commenté le grand Newton») y es «un traité de paix entre Descartes, Leibniz et Newton» (Locqueneux, 1995; Gardiner, 2008), porque en esta obra, destinada a servir de manual para su hijo, a quien se lo dedica, trata de conciliar la física de Newton con la metafísica de Leibniz, cuyo modelo de pensamiento fue un verdadero hallazgo para ella, ya que le permitió conectar los temas filosóficos y metodológicos expuestos en la primera mitad de la obra con las teorías físicas explicadas en la segunda. Una metafísica compatible con la física de Newton, que ayudaba a completarla y a eliminar sus contradicciones posibilitando encontrar respuestas adecuadas e inteligibles a preguntas $^{27}$ que hasta entonces sólo se podían contestar apelando a la voluntad divina o a los límites del conocimiento humano. La obra se convirtió en una introducción innovadora a la nueva física, que analizaba cuestiones como las propiedades de la materia, la naturaleza de la explicación, el papel de las hipótesis, la función de Dios en el universo o la posibilidad de la voluntad libre en un mundo mecánico, sacando a la luz un conjunto de presupuestos metafísicos que, declarados o no, subyacían a todos los planteamientos científicos (Macarrón, 2009, Molero, 2003). Supo aunar en lo principal las teorías de los tres grandes sabios, y sin embargo siempre encontraba algo en sus teorías con lo que no estaba de acuerdo. Mientras que sus contemporáneos varones estaban cada uno a favor de solo uno de estos sabios y en contra de los otros dos, ella fue la primera en ver lo positivo de cada uno de ellos e intentar construir una teoría unificada.

La decisión de Mme du Châtelet de atreverse a intentar una síntesis de metafísica y física, de defender la compatibilidad de las posiciones de Newton y Leibniz fue de una gran originalidad y valentía. Su afán de someter a discusión pública

\footnotetext{
${ }^{25}$ Publicado en 1740 «ce premier tome étoit prêt à être imprimé dès le 18 septembre $1738 \ldots$ mais l'Auteur ayant voulu y faire quelques changements, me la fit suspendre; ces changements, avoient pour objet la Métaphysique de M. de Leibnits dont on trouvera une Exposition abregée au comencement de ce volume» (Avertissement du libraire).

${ }^{26}$ Con este trabajo participó en el concurso de la Académie Royale des Sciences de 1739, cuyo tema era Sur la nature du feu. Émilie y Voltaire, cada uno por su parte, enviaron sus textos, pero el premio lo obtuvo Euler, aunque, dada la calidad de los textos la academia decidió editarlos, cosa que no había sucedido nunca con una mujer. En este trabajo, de 140 páginas había dos ideas fundamentales: la luz y el calor tenían una causa común y los rayos de distintos colores no proporcionan el mismo grado de calor.

${ }^{27}$ ¿Cuáles son los constituyentes básicos del universo?, ¿qué hace posible la ley de la gravitación?, ¿cómo surge el movimiento a partir de una materia inerte y puramente pasiva?, ¿qué relación hay entre la materia y el pensamiento?, ¿cómo es posible la libertad humana en un mundo mecánico?
} 
ambas doctrinas dejando a un lado los prejuicios supuso uno de los últimos episodios de una batalla que se libraba para no desvincular ciencia y filosofía, de la que Wolff constituirá su representante más destacado. Finalmente, los «positivistas» ganaron y dejaron establecido como axioma que la filosofía y la ciencia habían de tomar caminos distintos (Macarrón, 2009: 57).

A raíz de la publicación de esta obra y del debate (primer debate científico público entre un hombre y una mujer) con el secretario de la Academia, Dortous de Mairan ${ }^{28}$, en la carta que éste le escribió y publicó (Mairan: 1741) sobre la teoría de las fuerzas o vis viva ${ }^{29}$, polémica recogida en la reedición y que se extendió a otros países gracias a la traducción de la obra al alemán e italiano, es elegida miembro de la Academia de ciencias de Bolonia ${ }^{30}$ (la única en Europa que admitía a mujeres) en 1746 (en el mismo año en que Voltaire entra en la Académie française) y, posteriormente, de la Académie de Stanislas (Société Royale des Sciences et Belles-Lettres de Nancy).

La traducción de los Principia Mathematica de Newton -la única que existió en francés hasta hace muy poco- fue la obra de mayor envergadura de Émilie. Empezó la traducción en 1745 y la dio por terminada en 1749 tras haber intensificado el trabajo los últimos meses ante el peligro que intuía por su inminente parto (a pesar de que ya había tenido tres hijos, dada su edad, temía un mal desenlace) y la envió, pocas horas antes de su muerte ${ }^{31}$ y fechada por ella con el 10 de septiembre de 1749, al conservador de la Bibliothèque du Roi (actual Bibliothèque Nationale de France), Abée Sallier ${ }^{32}$, para dejar constancia de su autoría. Fue

\footnotetext{
${ }^{28}$ Apoyado por el también cartesiano Abbé Deidier, que también refutaba la existencia de fuerzas vivas, mientras que König y Maupertuis apoyaron a Émilie.

${ }^{29}$ Formulación primitiva del principio de conservación de la energía, propuesta por Leibniz -y formulada como proporcional al producto de la masa por el cuadrado de la velocidad- (en esa búsqueda filosófica de resolver el relativismo encontrando un parámetro constante, fijo e inamovible para poder compararlo con lo que cambiaba a o se movía y que para Descartes era la cantidad de movimiento, siempre la misma, que Dios había dado al universo y para Newton el espacio y el tiempo). Posteriormente las fuerzas vivas se denominaron «energía cinética» y las fuerzas muertas «energía potencial».

${ }^{30}$ En 1745, un año antes, había sido admitida Laura Bassi, divulgadora de las ideas newtonianas en Italia, primera mujer que obtuvo una cátedra de física en la universidad, donde llegó a impartir clases (uno sus alumnos fue Alessandro Volta).

${ }^{31}$ A principios de 1748, Émilie inició una relación sentimental con el joven poeta Saint-Lambert (hacia 1744 su relación con Voltaire se había roto porque éste mantenía una relación con su sobrina Madame Denis) y en 1749 se quedó embarazada e intensificó el trabajo porque temía que el parto fuera fatal. El parto tuvo lugar el 3 de septiembre de 1749 y una semana más tarde empezó a tener fiebre muy alta (posiblemente fiebres puerperales), muriendo a las pocas horas. Su hija murió poco después.

32 «J'use de la liberté que vous m'avez donnée, Monsieur, de remettre entre vos mains des manuscrits que j'ai grand intérêt qui restent après moi. J'espère bien que je vous remercierai encore de ce service et que mes couches, dont je n'attends que le moment, ne seront pas aussi funestes que je le crains. Je vous supplierai de vouloir bien mettre un numéro à ces manuscrits et les faire enregistrer
} 
publicada póstumamente en 1759 (Courcelle, 2008). Esta traducción, que Émilie consultó y verificó con Clairaut, Bernouilli y Jacquier, presentaba una gran dificultad, no sólo por el latín de Newton, no siempre claro y poco adaptable a los nuevos conceptos, sino porque Newton era muy dependiente de la geometría euclidiana y porque era necesario también hacer una traducción del antiguo lenguaje científico al nuevo, de modo que donde Newton multiplicaba las figuras geométricas euclidianas, Émilie utilizó, para mayor claridad, fórmulas analíticas y el sistema de notación propuesto por Leibniz para el recién descubierto cálculo diferencial e integral ${ }^{33}$.

Émilie acompañó esta traducción con un comentario ${ }^{34}$ de 180 páginas, Synthèse commentée et analyse des Principia par la marquise du Châtelet, que consta de dos partes: Exposition abregée du Système du Monde et explication des principaux phénomènes astronomiques tirée des Principes de M. Newton, seguido de Solution analytique des principaux problemes qui concernent le Systeme du Monde -donde incluye referencias a obras científicas recientes y actualizaciones como la de Bernoulli acerca de las mareas- que dejaban claro su gran conocimiento del estado de la cuestión, su excelente comprensión del pensamiento de Newton, y también sus reparos como, por ejemplo, el que opone a los cálculos de Newton sobre el movimiento de precesión de los equinoccios, que estima requerirían observaciones a más largo plazo e instrumentos de mucha mayor precisión (Hermann, 2008; Touzery, 2008).

En una carta a Federico II de Prusia, fechada el 15 de octubre de 1749, Voltaire (1975: 122) dijo de su amante que era «Un grand homme qui n'avait de défaut que d'etre femme». Madame de Châtelet fue una mujer, una gran mujer; una mujer que supo superar las limitaciones familiares, sociales y culturales propias de su sexo, aunque murió prematuramente por causas inherentes a su sexo.

afin qu'ils ne soient pas perdus. M. de Voltaire qui est ici avec moi vous fait les plus tendres compliments, et moi je vous réitère, Monsieur, les assurances des sentiments avec lesquels je ne cesserai jamais d'être votre très humble et très obéissante servante. Breteuil Du Châtelet. À Monsieur l'Abbé Sallier à la Bibliothèque du roi à Paris » (Catalogue de l'Exposition Émilie du Châtelet: 87).

${ }^{33}$ El cálculo infinitesimal (cálculo diferencia y cálculo integral) fue objeto de una discusión (controversia del cálculo) entre Newton y Leibniz (ambos afirmaban haberlo creado). De hecho, ambos habían descubierto el cálculo de forma independiente. Newton entre 1666 y 1669, y para 1671 ya tenía escritos dos libros, aunque el primero no se publicó hasta 1704 y el segundo hasta 1736 (9 años después de su muerte). Leibniz descubrió el cálculo entre 1675 y 1676, pero publicó sus descubrimientos antes, en 1684 y 1686 . Ambos sintetizaron los conceptos de derivada y de integral como conceptos inversos (teorema fundamental del cálculo) y desarrollaron las herramientas que permiten manejarlos. Pero utilizaron sistemas diferentes de notación y prevaleció el de Leibniz. Por ejemplo, frente a la notación de Newton con un sistema muy poco eficaz de puntos, Leibniz propone para la integral el símbolo $\int$, el símbolo dx para representar incrementos infinitesimales de $\mathrm{x}$ y el símbolo $\Delta \mathrm{x}$ para representar incrementos finitos de $\mathrm{x}$ (esta notación fue la utilizada por Madame de Châtelet).

${ }^{34}$ Dice Voltaire en el prefacio de la traducción: «On a vu deux prodiges: l’un que Newton ait fait cet ouvrage; l'autre qu'une dame l'ait traduit et l'ait éclairci» (apud Newton, 1759 : V). 
Una mujer sabia y tenaz que aprovechó el privilegio de haber podido formarse para proyectar y divulgar sus conocimientos y su sabiduría, pero que tuvo que reivindicar y velar por la autoría de sus trabajos.

Una mujer que buscó la armonía entre la literatura y la ciencia, las artes y las técnicas, la metafísica y la física. Una mujer que quiso desdibujar la dicotomía que en aquel entonces se estaba formando entre ciencias y letras.

Una mujer traductora de palabras y conceptos, de constataciones y creencias, de letras y números y capaz de transformar la geometría en el nuevo cálculo, en el gozne de esa revolución científica que se fraguó transitando de las generaciones de Euclides a las de Leibniz, de las teorías de Ptolomeo a las de Newton, del latín al francés y de éste a otras lenguas.

\section{Cambio de paradigma en química}

Si el cambio de paradigma en física había girado (nunca mejor dicho) en torno a la necesidad de conocer, medir y predecir la mecánica (movimiento, equilibrio y fuerzas) de los cuerpos celestes y terrestres, la revolución química, que tarda un siglo más en cristalizar, trata de dejar atrás los conceptos clásicos de elemento, principios... y busca una sistematización y unificación de medidas y denominaciones, métodos de análisis y definición de elementos.

A lo largo de la Edad Media, los elementos seguían siendo los cuatro definidos por Aristóteles: tierra, agua, aire (los tres estados de agregación de la materia: sólido, líquido, gaseoso) y fuego (impulsor de los cambios: energía) y combinaciones de dos pares de propiedades opuestas: frío y calor, humedad y sequedad, aunque algunos alquimistas ${ }^{35}$ habían propuesto listas alternativas de principios elementales, como Paracelso y sus seguidores que creían que todos los cambios químicos se debían a la combinación de la Tria prima, comunes a todas las sustancias: sal (el cuerpo); azufre (el alma) y mercurio (el espíritu), y que todo lo que se quemaba era azufre.

El aire era considerado un elemento homogéneo e inerte, hasta que el belga Van Helmont (1580-1644) observó que haciendo arder madera obtenía vapores sin volumen ni forma que parecían aire, pero que no se comportaban igual y, para distinguirlos, los llamó gases, siendo el primero en hacer la distinción entre aire y gas, inaugurando la llamada química neumática.

Esto había sido posible gracias al perfeccionamiento de los instrumentos que se utilizaban en los laboratorios de química (hornos, redomas, cucúrbitas o retortas, campanas, alambiques...) que ya tenían larga historia, porque eran los utilizados por la alquimia, y los aparatos de medir, fundamentalmente la balan-

\footnotetext{
${ }^{35}$ La al-kimiya llegó a Europa a través de los árabes y su preocupación era la transmutación de los metales (de preferencia en oro) y, para conseguirlo, se necesitaba una sustancia desconocida, un al-iksir (elixir), que en Europa se llamó piedra filosofal y que además serviría para curar todas las enfermedades. Georgius Agricola había sustituido en sus trabajos en latín (desde 1530) los términos alchymia y alchymista, por chymia y chymista, pero sólo con el propósito de devolver las palabas a sus raíces clásicas. Finalmente, Robert Boyle suprimió la primera sílaba del término «alquimia» en The Sceptical Chymist (1661).
} 
$\mathrm{za}^{36}$-para determinar los pesos-, el areómetro - para medir la densidad de los líquidos-, probetas, pipetas y buretas - para medir volúmenes.

Estos descubrimientos del siglo XVII llevaron a los químicos a una nueva conciencia del fuego. ¿Por qué algunas cosas arden y otras no? ¿Cuál es la naturaleza de la combustión? El fuego, además de uno de los cuatro elementos aristotélicos, era considerado un cuerpo aparte que podía mezclarse con otros cuerpos, es decir, todo lo que puede arder contiene el elemento fuego (el principio filosófico azufre, no necesariamente el azufre real) que se libera en determinadas condiciones. (Asimov, 2010).

Stahl (1660-1734), químico alemán, propuso otro nombre para el principio de la inflamabilidad, el flogisto, de una palabra griega que significa «hacer arder» y desarrolló un esquema basado en el flogisto que explicara la combustión: los objetos combustibles eran ricos en flogisto -cuanto más flogisto tuviese un cuerpo, mejor combustible era- y los procesos de combustión suponían la pérdida de flogisto en el aire. Lo que quedaba tras la combustión no tenía flogisto y, por tanto, no podía seguir ardiendo. Así, la madera tenía flogisto, pero las cenizas no. El fuego, según Stahl, no era un elemento, sino un instrumento y el flogisto el ingrediente material sobre el que actuaba el fuego. El flogisto, materia y principio del fuego, pero no el fuego en sí, estaba presente en todos los cuerpos combustibles y en los metales y era el mismo para todos ellos. El producto de la combustión podía restaurarse, reconvertirse en la sustancia original, si se le añadía flogisto proveniente de cualquier material que lo contuviera: aceite, carbón, hollín (Aréchiga, 2007).

Los escritos de Stahl (Zymotechnia Fundamentalis Oder Allgemeine Grund-erkänntniß Der Gährungs-kunst, 1697 y Fundamenta chimiae dogmaticae et experimentalis, de 1723), mezcla de latín y de alemán son difíciles de descifrar, aunque este último fue muy divulgado. El francés Rouelle (1703-1770), impartió un curso sobre la revolución stahliana que tendrá una gran influencia y al que asistirán, entre otros, Diderot y Lavoisier, quienes aprenden allí química. A partir de este curso se difundirá la química stahliana y cada químico añadirá retoques y sus marcas personales a la teoría. Rouelle, por ejemplo, hará del flogisto un principio con dos funciones: la de ser un compuesto de las mezclas, y la de ser instrumento de las reacciones químicas.

La teoría del flogisto ganaba adeptos, entre otras razones porque tenía una utilidad práctica para los químicos, ya que permitía explicar fenómenos como la fundición, la fermentación o la calcinación y la alcalinidad que, hasta entonces, no parecían estar relacionados, de modo que hacia mediados del siglo

\footnotetext{
${ }^{36}$ En 1750 el químico escocés Joseph Black desarrolló la balanza analítica (para medir pequeñas masas con poco margen de error) y Lavoisier aumentó su precisión, con idea de exportar a la química los avances de la física experimental, aplicando las matemáticas a la medición de datos e instaurando una química cuantitativa. Para ello encargó la construcción de tres balanzas más sofisticadas y mejor adaptadas a los diferentes usos (una con una sensibilidad de $20 \mathrm{mg}$. para $10 \mathrm{~kg}$., otra con una sensibilidad de $5 \mathrm{mg}$. para 600 gr. y otra de $0,1 \mathrm{mg}$. para 4 gr.).
} 
XVIII esta teoría era ampliamente aceptada por los químicos, si bien fue objeto de una serie de modificaciones (Aréchiga, 1994).

Pero había un problema que ni Stahl ni sus discípulos pudieron resolver. La combustión de la madera, con la subsiguiente pérdida de flogisto, producía cenizas que pesaban menos que la madera. Sin embargo, en la calcinación de los metales dando lugar a la formación de la correspondiente cal, la pérdida de flogisto producía un aumento de peso. ¿Había entonces dos tipos de flogisto: el de la madera y otras sustancias, con peso positivo (la sustancia, al desprender el flogisto perdía peso), y el de los metales, con peso negativo (la sustancia, al desprenderlo ganaba peso)?

Fue el químico francés Lavoisier ${ }^{37}$ (1743-1794), considerado el padre de la química moderna (Bensaude-Vincent, 1991; Bertomeu, 2006; Best, 2011) quien demostró que la teoría del flogisto era errónea y que el flogisto no existía, reconsiderando el proceso de combustión (y de oxidación), y definiéndolo como una reacción química entre cualquier compuesto y el oxígeno ${ }^{38}$. Cuando, en 1777, Lavoisier publicó por primera vez su teoría de la combustión, Réflexions sur le phlogistique, pour servir de suite à la théorie de la combustion et de la calcination, lo llamó el «principio de oxígeno» (a partir del prefijo griego oxi-, que significa «ácido» y el sufijo - genes, «generador»).

Él fue quien enunció la primera ley básica de la química de conservación de la masa o la materia -al comprobar que cuando un metal se oxida al aire, la ganancia de peso del material obtenido es igual al peso que pierde el aire-: la materia no se crea ni se destruye durante una reacción química, sólo se transforma.

Él fue quien consiguió demostrar que el agua no era un elemento porque se podía descomponer en los dos gases que más tarde llamaría hidrógeno (generador de agua) y oxígeno (generador de ácido).

Él fue quien fundó una nueva química experimental basada en la composición y descomposición de sustancias y definió por fin el concepto de elemento químico (el que no se puede descomponer en partes más pequeñas) frente a la sustancia compuesta y quien caracterizó como elemento químico, además del oxígeno y el hidrógeno, el nitrógeno ${ }^{39}$, el fósforo, el mercurio, el zinc y el azufre.

Él fue quien, junto con sus colaboradores, elaboró un sistema de nomenclatura (que será la base de la tabla periódica de Menleléyev) Méthode de nomenclature chimique $^{40}$, publicado en 1787 para facilitar un intercambio de información precisa y generalizable.

\footnotetext{
${ }^{37}$ Su nombre es uno de los setenta y dos (científicos, ingenieros e industriales franceses que realizaron aportaciones relevantes entre 1789 y 1889) grabados en la torre Eiffel.

${ }^{38}$ El oxígeno fue descubierto en 1772 (y publicado en 1777) por el sueco Carl Wilhelm Scheele, quien lo denominó «aire del fuego». Por su parte, poco después, en 1774 (y publicado en 1775), también lo descubrió el británico Joseph Priestley, llamándolo «aire desflogistizado».

${ }^{39} \mathrm{Al}$ que llamó azote (sin vida), nombre que persiste en francés.

${ }^{40}$ En el cuadro (anónimo) que reproduce a los autores de Méthode de nomenclatura chimique están retratados los científicos M. Lavoisier (sentado), M. Guyton de Morveau, M. Berthollet y M.
} 
Él fue quien sistematizó en Traité élémentaire de Chimie (1789) los conceptos químicos conocidos en la época como una ciencia racional y sistemática.

A los 51 años, en 1794, fue guillotinado, junto con otros 27 recaudadores de impuestos (fermiers généraux ${ }^{41}$ ) entre los que se contaba su suegro. «Il a fallu un instant pour couper sa tête, et un siècle ne suffira pas pour en produire une si bien faite», dijo el matemático Lagrange (apud Leduc, 2013: 154). Un año y medio después, el nuevo gobierno rehabilitó su figura, y devolvió a Marie-Anne Lavoisier sus efectos personales con una nota: «À la veuve de Lavoisier, qui a été condamné à tort».

\section{Madame Lavoisier en el gozne del cambio de paradigma}

Lavoisier, padre de la química moderna o, dicho de otro modo, personaje sobresaliente en la cristalización de la revolución científica química coincidió, por vía de recuperación, colaboración, oposición, o ignorante casualidad, con muchos nombres que configuraron esa revolución: Van Helmont, Boyle, Mariotte, Cavendish, Becher, Stahl, Scheele ${ }^{42}$, Berthollet, Guyton de Morveau, el conde de Fourcroy, Laplace, Lagrange... Todos ellos -que comparten la característica de ser varones y reconocidos científicos- fueron aportando su ciencia a la construcción del nuevo paradigma cuya paternidad, sin embargo, se atribuye al francés Lavoisier.

Y en esa constelación de nombres conocidos y reconocidos, otra secundaria, otra mujer, otra traductora, otra estrella tenue de esa vía láctea conforma el gozne que articuló el cambio de paradigma, Marie-Anne Pierrette Paulze (17581836), nacida 10 años después de la muerte de Madame de Châtelet y casada con Lavoisier en 1771, a los 13 años.

Marie-Anne aprovechó este temprano matrimonio para continuar la formación convencional dispensada a las mujeres de clase alta que había recibido en un convento y, como estaba interesada por las actividades de su esposo, la completó estudiando pintura y dibujo con Jacques-Louis David ${ }^{43}$ y química con Bap-

Fourcroy, así como las traductoras Mme Lavoisier y Mme Picardet: https://www.pourlascience.fr/sd/histoire-sciences/madame-picardet-traductrice-scientifique-ou-cosmetique-des-lumieres8227.php.

41 Titulares de una cesión de una compañía privada francesa del antiguo Régimen, la Ferme Générale, encargada de la recaudación y la gestión de impuestos (concretamente los impuestos indirectos: sal, tabaco, alcohol, entrada y tránsito de mercancías...).

${ }^{42}$ Mémoires de chymie de M. C. W. Scheele (1785) traducido del sueco en dos tomos por Claudine Poullet (luego Picardet y luego Guyton de Morveau) (1735-1820), prolífica traductora científica no sólo de sueco, sino de alemán, inglés e italiano. Hasta 1786 no reclamó su identidad y figuró como Mme P o Mme P*** de Dijon.

${ }^{43}$ David (1748-1825), autor, por encargo de Marie-Anne, del Portrait d'Antoine-Laurent Lavoisier et de sa femme (1788) es el pintor de la revolución francesa: Le Serment du jeu de paume (1791), La mort de Marat (1793)... y luego de Napoleón: Bonaparte franchissant le Grand-Saint-Bernard (1800-1803), Le Sacre de Napoléon (1808), Napoléon dans son cabinet de travail (1812), entre otros. 
tiste Bucquet ${ }^{44}$, de modo que, a su formación en humanidades e idiomas, añadió sólidos conocimientos científicos y de diseño. Marie-Anne se convirtió en colaboradora, asistente, traductora, editora, ilustradora y secretaria de su marido. Por el laboratorio personal ${ }^{45}$ de Lavoisier, primero en la rue Bons-Enfants y finalmente en el Arsenal de París, (Troitiño, 2007) pasaron matemáticos como Lagrange y Meusnier, químicos como Berthollet, Guyton de Morveau, Séguin, Trudaine, Priestley... naturalistas como von Humboldt y Cuvier, físicos como Arago, Vicq d'Azyr, Benjamin Franklin, por entonces embajador en París, o Jacinto de Magallanes (descendiente de Fernando de Magallanes), el médico Macquer, el farmacéutico Cadet de Gassicourt, economistas como Dupont de Nemours ${ }^{46}$ además de sus colaboradores: Laplace, Fourcroy, Monge...

Como ilustradora, su trabajo más significativo son los 13 grabados $^{47}$ en cobre firmados "Paulze Sculptis" para el libro Traité élémentaire de Chimie (1789), que es considerado como la primera obra de la química moderna. Se trata de detallados dibujos de instrumental de laboratorio: embudos, frascos, caloríme$\operatorname{tros}^{48}$, aparatos de filtrado, sifones, etc., de gran utilidad para que otros científicos pudieran entender los métodos y resultados de Lavoisier y reproducir los instrumentos y los experimentos. Hacia 1790 dibujó al menos dos escenas de cómo era un día de trabajo en el laboratorio del Arsenal, donde se ve a Lavoisier y a sus colaboradores (Laplace, Séguin...) investigando los procesos químicos de la respiración (y son el único testimonio gráfico del instrumental empleado en los experimentos con respiración humana que Lavoisier llevó a cabo en esa época). En el dibujo, Marie se representó en un segundo plano, tomando nota de cuanto sucedía en el gabinete.

Pero no solo hizo esto; Lavoisier no dominaba otros idiomas, pero MarieAnne sí: latín, inglés, italiano y alemán, lo que le permitió conocer, y dar a conocer, de primera mano los textos de los ingleses que en aquellos momentos lideraban la teoría del flogisto de Stahl como principio de la combustión: Priestley, Schelle, Cavendish... De hecho, Priestley pudo compartir con Lavoisier sus conclusiones del experimento de la cal de mercurio gracias a la mediación de MarieAnne, quien también se ocupó de traducir (o escribir) la correspondencia que se

\footnotetext{
${ }^{44}$ Bucquet (1746-1780), profesor de química en la Universidad de París (entre sus alumnos se encuentran Fourcroy y Berthollet), colaboró con Lavoisier desde 1777, y fue el primero en incorporar la teoría de la combustión en sus clases.

45 Espléndidamente dotado (los ingresos de Lavoisier por sus cargos públicos y como fermier général eran elevados).

$46 \mathrm{Su}$ hijo, Éleuthère Irénée, fue colaborador de Lavoisier y fundó una fábrica de pólvora en EEUU, Dupont, actualmente una multinacional que abarca diversas ramas químicas, como la fabricación de materiales como neopreno, nylon, lycra, plexiglás, teflón, kevlar (esta última fue sintetizada por una mujer, Stephanie Kwolek, en 1965. Se utiliza para chalecos antibalas, botas de alta montaña, guantes aislantes térmicos, trajes espaciales...).

${ }^{47} \mathrm{En}$ : http://othmerlib.chemheritage.org.

${ }^{48}$ Instrumento ideado por él y Laplace.
} 
intercambiaron Lavoisier y Kirwan y los artículos de científicos como Henry Cavendish o Joseph Black.

De ello da testimonio Arthur Young, economista inglés que visitó a Lavoisier en 1787: «Madame Lavoisier, une personne pleine d'animation, de science et de savoir, nous avait préparé un déjeuner anglais au thé et au café, mais la meilleure partie de son repas, c'était, sans contredit, sa conversation, soit sur l'essai sur le phlogistique de M. Kirwan qu'elle est en train de traduire, soit sur d'autres sujets qu'une femme de sens travaillant dans le laboratoire de son mari sait si bien rendre intéressants» (Ruelland, 2004: 103). Y también el químico y botánico suizo Nicolas-Théodore de Saussure, a quien había enviado un ejemplar y que no solo la felicita por la traducción, sino que se declara convencido de la inexistencia del flogisto: «Vous triomphés de mes doutes, Madame, au moins sur le phlogistique, principal objet de l'intéressant ouvrage dont vous m'avés fait l'honneur de m'envoyer un exemplaire. [...] je ne puis pas m'empêcher de trouver que malgré la grâce et la précision avec lesquels vous avés rendu son livre, l'honneur que vous lui avés fait, Madame, de le traduire est funeste à sa réputation» (Kawashima 2000: 239-240).

El irlandés Kirwan (1733-1822), uno de los químicos más brillantes de la época, responde en 1787 a la Réflexion sur le phlogistique pour servir de suite à la théorie de la combustion et de la calcination, publiée en 1777 de Lavoisier (publicada en 1786 y presentada en la Académie des Sciences en 1783) con su Essay on Phlogiston and the Constitution of Acids, donde defiende las ideas de Stahl, identificando el hidrógeno con el flogisto y dedicando buena parte de su libro a tratar de determinar la presencia del hidrógeno/flogisto en todas las sustancias combustibles. Además, reconociendo que la hipótesis antiflogística de Lavoisier era «de una sencillez encomiable», no dejaba de desacreditarla por ser «más arbitraria en cuanto a su aplicación y menos tolerable con arreglo a las reglas generales del razonamiento filosófico» que la teoría stahliana del flogisto (Smartt 2013).

Y se produce un cisma: Inglaterra, Alemania y Suecia se decantan por la teoría de Kirwan, frente a Francia -deseosa de mantener su ilustrada hegemonía cultural, científica, literaria, social... empañada por el debate perdido tras las expediciones a Laponia y Perú para determinar el achatamiento de la tierra (cartesianos derrotados por newtonianos)-, así que Lavoisier y sus colegas deciden cerrar filas y rebatir esta obra, para lo que necesitan traducirla.

Marie-Anne es la traductora, pero la traductora anónima, ya que su nombre no figura en la primera edición, que se publica en 1788 con el título Essai sur le phlogistique et sur la constitution des acides, traduit de l'anglois de M. Kirwan; avec des notes de MM de Morveau, Lavoisier, de la Place, Monge, Berthollet \& de Fourcroy.

El texto abre con una Préface du Traducteur, sin precisar quién fue dicho traductor, que describe los descubrimientos químicos y donde se dice respecto a la traducción: 
[...] on s'est appliqué à la rendre [la traduction] aussi littérale que la différence des langues a pu le permettre et à exprimer de la manière la plus claire et la plus précise les idées de M. Kirwan: l'extrême exactitude qu'exigent les matières scientifiques, oblige a la plus grande sévérité dans le choix des expressions. Mais ce travail n'auroit pas suffisament avancé la révolution qui se prépare en Chimie, et le but d'utilité qu'on se proposoit, n'eût pas été rempli, si l'on n'eût joint à la traduction de l'Ouvrage de M. Kirwan, les observations auxquelles il pouvoit donner lieu [...] Le Traducteur ne s'est permis que quelques notes peu importantes (Kirwan, 1788) ${ }^{49}$.

Como se puede apreciar, no se refieren a problemas de traducción, sino que son precisiones técnicas, puntualizaciones, sobre errores químicos detectados.

La obra sigue con una introducción, 12 secciones y la conclusión, cada una de las cuales va seguida de Notes, Observations o Remarques de alguno de los autores que figuran en el título; es decir, es una enmienda a la totalidad por partes.

En 1789 Kirwan publicó una nueva edición de su tratado que incluía los comentarios franceses y una tentativa de refutarlos, aunque daba ya muestras de rendirse. En 1791, Kirwan escribió a Berthollet: «Enfin je met bas les armes \& j'abandonne le flogiste» (Kawashima, 2000: 240). Para entonces, la mayoría de los químicos ya lo había abandonado y Lavoisier (y Francia) salía victorioso de una lucha de quince años contra los partidarios del flogisto.

Marie-Anne también traduce en 1790, del mismo Kirwan, los artículos De la force des acides et de la proportion des substances qui composent les sels neutres, y Suite du Mémoire sur la force des Acides \& sur la proportion des substances qui composent les sels neutres, publicados en los Annales de Chimie ${ }^{50}$ (vol. 14, 1792), que llevan la firma de Madame L.

Madame Lavoisier, tras la detención y decapitación de su esposo y de su padre, fue despojada de todos sus bienes y también detenida y encarcelada durante

${ }^{49}$ En total dos notas:

Pag 44: $2^{\circ}$. La seule substance qui s'unit au principe oxigène à toutes les tempérarures, \& qui chasse constamment le principe de la chaleur, est l'air nitreux $(*)$.

Pag. $45(*)$ L'air nitreux ne chasse qu'une très-petite portion de la chaleur dans l'air vital, ou gaz oxigène. Cette même chaleur se retrouve dans toutes les décompositions de l'acide nitreux \& elle est même susceptible d'être mesurée. (Note du traducteur).

Pag. 58: II est donc impossible de supposer que toute l'eau obtenue existât dans ces gaz, c'est-àdire, que sur 50 parties il y en eut 49 d'eau. D'après M. Lavoisier, 100 parties d'eau en poids contiennent environ 87 parties d'air déphlogistiqué, \& 13 de gaz inflammable: ce qui est à-peu-près dans la proportion de 7 à 1 (b)

Pag. 58-59 (b) Les expériences faites au commencement de 1785, en présence des Commissaires de l'Académie des Sciences de Paris, donnent environ en poids 85 d'air vital, \& 15 de gaz inflammable. Cette expérience peut être regardée comme aussi exacte que celle de M. Monge (Note du traducteur).

${ }^{50}$ Revista científica fundada en 1789 en París, uno de cuyos primeros editores fue Lavoisier, dedicada a la publicación monográfica de la nueva química. 
65 días. Cuando Lavoisier fue rehabilitado y Marie-Anne recuperó sus bienes, se dedicó a reunir y publicar los trabajos de su marido bajo el título Mémoires de Chimie, de las que se publicaron dos volúmenes: el primero que incluye los trabajos sobre el calor y la formación de los líquidos y el segundo que trata sobre la composición del aire, la calcinación de los metales y la acción de los ácidos. En la primera versión, Madame Lavoisier escribió un prólogo bastante ofensivo que atacaba y acusaba a los que ella consideraba responsables de su muerte al haber abandonado a Lavoisier cuando éste estuvo detenido: Fourcroy, Guyton de Morveau, Monge... En la reimpresión de 1805 sustituye ese prólogo por una cita de Lavoisier: «cette théorie n'est donc pas, comme je l'entends dire, la théorie des chimistes français; elle est la mienne et c'est une propriété que je réclame auprès de mes contemporains et de la postérité ${ }^{51 .}$

Si fue posible que Adolphe Wurtz (1817-1884), catedrático de Química Orgánica en la Universidad de la Sorbona e impulsor y coordinador del Dictionnaire de chimie pure et appliquée, empezara el Discours préliminaire de dicho diccionario con la frase: «La chimie est une science française: elle fut constituée par Lavoisier, d'immortelle mémoire» (1869-1908: 1), se debe sin duda a que éste contó con magníficos colaboradores y colegas, y también con una mujer, MarieAnne -considerada en el mejor de los casos como «una eficaz colaboradora»que, desde la sombra (voluntaria o impuesta), contribuyó a la revolución científica de la química.

Con sus conocimientos lingüísticos, traduciendo textos científicos que requerían una sólida formación, ejerciendo como intérprete en debates, trasmitiendo opiniones y reparos, en una mediación cultural y científica que facilitó las tareas y los trabajos del equipo del que era parte sin formar parte.

Con su talento para el dibujo y el grabado, arte al servicio de la ciencia, que puso al alcance de todos los científicos en un momento de creación de nuevos utensilios y nuevos procedimientos necesarios para plasmar los nuevos experimentos químicos, que había que comprender, repetir y contrastar para consolidar o refutar conceptos, traduciendo al lenguaje gráfico las necesidades instrumentales de la nueva química de precisión.

Con su perseverancia y capacidad para la divulgación, recogiendo y editando la obra de su marido, sin muchos más apoyos al principio que su propia tenacidad, pero sabiendo la trascendencia de esa obra para el futuro y la enseñanza de esa nueva química.

Una mujer traductora en el gozne de esa revolución científica que transitó de la alquimia a la química, del flogisto al oxígeno, de la imagen a la palabra, de la tarea minuciosa, paciente y oscura del laboratorio a la tarea comprometida, valiente y trascendente de la divulgación.

\section{Otras estrellas de la vía láctea}

${ }^{51}$ Journal des savants, t. 2. Octubre de 1824, p. 604. 
En noches claras se puede ver una franja blanca que atraviesa el cielo de lado a lado. Si la Tierra fuera transparente, se podría percibir como un cinturón blanquecino. Es la Vía Láctea, una aglomeración de estrellas en forma de espiral aplanada y tan pegadas las unas a las otras que casi no se pueden distinguir entre sí.

Según la mitología griega la leche de Hera, la esposa de Zeus, el dios de dioses, se derramó cuando retiró de su pecho a Heracles (Hércules), el hijo bastardo que Zeus había tenido con la mortal Alcmena. Hermes, el mensajero de los dioses, había aprovechado que Hera dormía para que Hércules mamase su leche y así obtuviese la inmortalidad. La leche derramada formó la Vía Láctea.

La Vía Láctea es la galaxia en la que vivimos, que contiene miles de millones de estrellas, incluyendo nuestro Sol. Y se mueve.

Y en este movimiento, a veces desconcertante, de la Vía Láctea ${ }^{52}-\ll$ La Voie Lactée, par exemple, est un ensemble de Soleils dont les mouvements semblent d'abord capricieux» (Poincaré, 1906: 4)-, prestando atención y disponiendo de un potente telescopio, se pueden focalizar algunas estrellas, desvelarlas, descubrirlas con más detalle, incluso ponerles nombre.

Vamos a poner nombre a tres de esas tenues estrellas que estuvieron en el gozne de ese movimiento generador de conocimiento, de ciencia, de saberes, y que conformó aquel paradigma científico en constante cambio y transformación.

La primera estrella es la escocesa Mary Fairfax Somerville (1780-1872).

Entre 1799 y 1825 el astrónomo, físico y matemático francés Laplace ${ }^{53}$, colaborador de Lavoisier, publica el Traité de mécanique céleste, monumental obra en 5 volúmenes aparecidos entre 1799 y 1825, que culmina el trabajo de más de un siglo de duración durante el cual los científicos intentaron dar una explicación matemática de la teoría de la gravitación universal basada en los principios de Newton. Laplace reúne en un solo cuerpo de doctrina homogénea todos los trabajos dispersos de Newton, Halley, Clairaut, D'Alembert, Euler, etc. De esta manera, y junto con sus propias aportaciones, recoge el conocimiento de su época sobre el movimiento de los cuerpos del Sistema Solar, despojándolo ya para siempre de toda intervención divina. Traité de mécanique céleste no es solamente la reformulación de los Principia de Newton mediante el cálculo diferencial (gracias a la traducción realizada por Madame de Châtelet que ya había «traducido» las demostraciones geométricas de Newton al lenguaje diferencia e integral de Leibnitz), sino que completa todos aquellos apartados que Newton fue incapaz de justificar en sus detalles.

El Traité de mécanique céleste, de difícil lectura y comprensión -Biot, que le ayuda en la revisión de los textos para su impresión, narra que, con

\footnotetext{
${ }^{52}$ En el Grand verre de Marcel Duchamp, la Voie lactée -en la mitad superior izquierda, expansión de la Mariée y cuya función es comunicar a los célibataires sus deseos y mandamientos-, es una nube, como un velo movido por el aire, de modo que no se sabe muy bien si su función es la de velar o la de desvelar.

${ }^{53} \mathrm{Su}$ nombre también es uno de los 72 grabados en la torre Eiffel.
} 
frecuencia, Laplace es incapaz de recuperar los detalles en su cadena de razonamientos por lo que rápidamente recurrirá a la fórmula: «Il est facile de voir» (Gómez 1998)-, gozó de dos traducciones al inglés (en Estados Unidos, por un varón, y en Gran Bretaña, por una mujer) que facilitaron su divulgación.

La traducción del varón (en cuyo detalle no vamos a entrar porque se aleja de nuestro propósito), el matemático autodidacta americano Nathaniel Bowditch (1773-1838) que, entre 1829 y 1839 publica cuatro volúmenes de la Mécanique Céleste by the Marquis de Laplace, translated with a commentary, tuvo la peculiaridad de distribuirse en Francia, donde fue más comentado y difundido que la versión original, precisamente por incluir referencias a los autores que Laplace utiliza, pero no cita (tablas astrológicas de Bürg y Buckhart, Principia de Newton, Mecánique Analytique de Lagrange, trabajos sobre el péndulo de Bernouilli, cálculos de la atracción ejercida por un elipsoide de Colin Maclaurin), mejoras en la tipografía, explicaciones de cálculos $\mathrm{u}$ operaciones que Laplace no incluye o no explica e introducción de actualizaciones de herramientas matemáticas o nuevos métodos de cálculo (Preveraud, 2015).

La otra traducción fue encargada a Mary Somerville en 1827 por el abogado Henry Brougham (que por entonces presidía la cámara de los Lores) en una versión condensada para la Society for the Diffusion of Useful Knowledge ${ }^{54}$. Ella aceptó el encargo tras muchas dudas, pero el resultado después de cuatro años era demasiado largo para publicarlo allí. Sir John Herschel consideró el libro excelente $^{55}$ y recomendó que se editara en edición convencional -la publicó John Murray en 1831 con el título Mechanism of the Heavens (1831)- y fue un éxito, alabado por matemáticos y astrónomos británicos ${ }^{56}$. La introducción de la Mecánica Celeste, en la que Somerville resumió el estado actual del conocimiento astronómico para el lector general, se publicó por separado en 1832 como A preliminary dissertation on the mechanism of the heavens ${ }^{57}$.

¿Quién era Mary Somerville para que le fuera encargada una obra de tal envergadura? Fue llamada por sus contemporáneos «la reina de las ciencias» (Alic, 1991, Lafortune, 1986), algo insólito para una mujer del siglo XIX. Hija de un vicealmirante escocés, destinada a tener una educación propia de su sexo (lenguas, dibujo, piano, costura y poco más), descubrió las matemáticas cuando el profesor de dibujo de su hermano le explicaba los elementos de Euclides para que

\footnotetext{
${ }^{54}$ Esta sociedad se había fundado en 1826 para publicar, a bajo precio, textos que divulgaran temas científicos entre un público amplio.

${ }^{55}$ Sirvió para introducir las matemáticas continentales a los lectores de habla inglesa y la Universidad de Cambridge utilizó esta obra como libro de texto en los cursos de matemáticas superiores.

${ }^{56}$ Entre otros: Clerk Maxwell, Charles Darwin, Michael Faraday, Sir Charles Lyell y John Stuart Mill.

${ }^{57}$ En esa Disertación Preliminar hizo un compendio de desarrollos matemáticos e ideas fundamentales de física imprescindibles para comprender la obra de Laplace, explicando con sencillez toda una teoría difícil de entender por el público común.
} 
entendiera la perspectiva, y de ahí pasó a estudiar álgebra, ayudada por el tutor de otro de sus hermanos. Unos años más tarde, viuda y con dos hijos, colaboró con el matemático William Wallace en la resolución de algunos problemas y recibió su primer reconocimiento, una medalla de plata, por la solución de un problema sobre las ecuaciones diofánticas.

Su segundo matrimonio, en 1812, con su primo William Somerville, fue un respaldo fundamental en su dedicación a la ciencia, ya que se convirtió en su principal ayudante y se hizo socio de la Royal Society (donde no se admitían mujeres $^{58}$ ) para copiar a mano los artículos que su mujer necesitaba para sus investigaciones.

En 1817 viajaron a París y conocieron a los más importantes matemáticos de la época como Lagrange, Poisson y Laplace. Para una científica como ella, el acceso y estudio de estos materiales era fundamental, dado que en Inglaterra, donde los discípulos de Newton estaban todavía empantanados en las poco prácticas demostraciones geométricas de su maestro, le resultaba muy difícil conseguir tratados matemáticos de esta importancia.

En 1826 Mary Somerville escribió su primer artículo The Magnetic Properties of the Violet Rays of the Solar Spectrum. Le siguieron Experiments on the Transmission of the Chemical rays of the solar spectrum across different media, $\mathrm{y}$ On the action of the Rays of the Spectrum on Vegetable juices, títulos que abarcan un gran espectro científico. Los publicó la Royal Society en Philosophical Transactions y eran los primeros escritos firmados por una mujer, lo que supuso un gran revuelo entre los científicos del momento. Estos trabajos no tenían detrás el aval de ninguna universidad, institución, o sociedad científica; sin embargo, el gran prestigio social que Mary Somerville alcanzó, le abrió las puertas de los salones londinenses, los únicos a los que podía acceder por el hecho de ser mujer. Muchos científicos se interesaron por sus puntos de vista y mantuvieron con ella una correspondencia regular, dirigida a su marido, eso sí, ya que no procedía que una mujer se carteara con varones.

Fue una de las pocas mujeres reconocidas por sus contemporáneos: miembro honoraria, junto con Carolina Herschel, de la Royal Astronomical Society ${ }^{59}$ en 1835, miembro honoraria de la Société de Physique et d'Histoire Naturelle de Genève en 1834, y ese mismo año miembro de la Royal Irish Academy. En 1870 fue nombrada miembro de la Società Geográfica Italiana. Incluso recibió una pensión de la Reina Victoria por su obra científica.

Otro de sus méritos es el de haber iniciado en las matemáticas a otra traductora «casual»-ya que su tarea como traductora fue muy concreta y se circunscribió a un único texto-, lo que nos lleva a la siguiente estrella.

La segunda estrella se llama Ada Byron King, condesa de Lovelace (18151852) (Alic, 1991). Hija única de Lord Byron, recibió clases, sobre todo de la rama de matemáticas y astronomía, contando entre sus tutores con el prestigioso

\footnotetext{
${ }^{58}$ Las mujeres no fueron admitidas hasta 1945.

${ }^{59}$ Se abrió a las mujeres en 1915.
} 
Augustus de Morgan, el primer profesor de matemáticas de la Universidad de Londres y con Mary Somerville. Su madre, Lady Annabella Byron, quería darle a su hija una formación científica para alejarla lo más posible del mundo de su padre, que era el de las letras. Ada ${ }^{60}$ conoció, a los 18 años de edad, al matemático Charles Babbage y quedó fascinada por sus proyectos para construir máquinas de cálculo: la máquina diferencial y la máquina analítica ${ }^{61}$ (esta última capaz de alterar su funcionamiento interno en base a las órdenes de lenguaje de programación, es decir, programable y que funcionaba con tarjetas perforadas como los telares de Jacquard $^{62}$ ) que nunca llegaron a construirse. Babbage informó de los avances de su trabajo en un seminario en Turín, Italia, en el otoño de 1841, mostrando por primera vez los planos de su máquina analítica capaz de sumar, restar, multiplicar y dividir, que revolucionarían el cálculo mecánico y anticipaban los actuales ordenadores. Un militar matemático e ingeniero italiano, Luigi F. Menabrea (que posteriormente se convertiría en primer ministro de Italia), publicó en francés un importante informe sobre el trabajo de Babbage en 1842: Notions sur la machine analytique de M. Charles Babbage, par Mr. L.F. Menabrea, capitaire, du génie militaire ${ }^{63}$. Ada, a instancias del propio Babbage, lo tradujo al inglés y, cuando éste vio la traducción, le sugirió que añadiera sus propios comentarios. El informe de Ada, publicado en 1843, acabó teniendo una longitud tres veces mayor que el original, y contiene muchas de las importantes predicciones de Ada con respecto a la Máquina Analítica de Babbage. Pero como en aquella época no se admitía que las mujeres escribieran artículos científicos, firmó como «A.A.L.».

Sus anotaciones hicieron un profundo análisis del invento y permitieron que fuera desarrollado: el motor analítico calculaba cualquier función algebraica y almacenaba números. Además, Ada predice que una máquina como ésta podría llegar a componer música, producir gráficos, y que podría llegar a ser utilizada tanto en el ámbito científico como en la vida diaria. Una de sus geniales ideas fue la de que un cálculo grande podía contener muchas repeticiones en la misma secuencia de instrucciones, y ella notó que usando un salto condicional sería posible preparar solamente un juego de tarjetas para las instrucciones recurrentes. Así describió lo que ahora llamamos un «bucle» y una «subrutina» ${ }^{64}$. El papel de Ada Lovelace en el desarrollo histórico de las computadoras modernas fue casi totalmente ignorado hasta 1979, cuando el Departamento de Defensa de los

\footnotetext{
${ }^{60}$ En 1835 se casó con William King, octavo barón de King, más tarde conde de Lovelace y pasó a llamarse lady Ada Augusta Byron King, condesa de Lovelace, de ahí su nombre (lady) Ada Augusta Lovelace (AAL).

${ }^{61}$ En 1910, el hijo de Babbage construyó una parte de la Máquina Analítica (sin memoria y no reprogramable), que calculó una lista con los múltiplos del número Pi.

${ }^{62}$ Telar mecánico inventado por J.M. Jacquard en 1801, que revolucionó la elaboración de tejidos como el damasco, brocado, piqué.

${ }^{63}$ Publicado en la Bibliothèque Internationale de Genève en 1842, t. 41, 352-376.

${ }^{64}$ Sus ideas fueron recogidas y ampliadas un siglo más tarde por el matemático británico Alan M. Turing en 1937 y por el americano John von Neumann en 1946, ambos fundamentales en el desarrollo del ordenador tal y como lo conocemos actualmente.
} 
Estados Unidos decidió utilizar su nombre (ADA) para el nuevo lenguaje de programación, que utilizarían como estándar para desarrollar su propio software interno.

Y la tercera estrella se llama Clémence Royer (1830-1902).

Realizó la primera traducción al francés del libro de Darwin On the Origin of Species by Means of Natural Selection, or the Preservation of Favoured Races in the Struggle for Life (1859) que, a partir de su sexta edición (1872), pasa a llamarse The Origin of Specie. Darwin quería traducir su obra al francés (idioma que todavía seguía teniendo un papel preponderante en la difusión de la ciencia) (Sniadecki 2013, Petit 2010), y el profesor francés exiliado en Inglaterra Pierre Talandier se ofrece como traductor, pero no tenía editor. Tampoco el nombre de la escritora y traductora francesa Louise Belloc prospera, ya que no acepta por considerar el libro demasiado técnico. Clémence Royer, radicada en Suiza, científica y conocedora de las obras de Lamarck ${ }^{65}$ y de Malthus, tiene editor, Guillaumin et Victor Masson, y se ocupa de la traducción cuya primera edición data de 1862, añadiendo un voluminoso prefacio ${ }^{66}$ - «donde sacaba conclusiones a las que Darwin no se había atrevido a llegar y que tardaría diez años en sistematizar hasta la publicación en 1871 de The Descent of Man, and Selection in Relation to Sex, un año después de que Royer publicara L'origine de l'homme et des sociétés» (Blanco, 2004: 88-89)- y notas a pie de página con comentarios más cercanos a las posturas de Lamarck que a las de Darwin. Darwin expresa su descontento en diversas cartas: al botánico americano Asa Gray, al zoólogo francés Armand de Quatrefages, al botánico británico Joseph Hooker y sugiere varias modificaciones y correcciones a Clémence para la segunda edición. Ella acepta hacer las modificaciones.

Algunas de esas modificaciones se refieren al título, que pasó de $D e$ l'origine des espèces ou des lois du progrès chez les êtres organisés a L'origine des espèces par sélection naturelle ou des lois de transformation des êtres organisés. $\mathrm{O}$ a algunos términos, en concreto el término élection que Clémence había utilizado y que cambia por sélection y que explica así, siendo, en cierto modo, la introductora en francés del término con ese significado ${ }^{67}$ :

Quant au terme de sélection, voyant qu'il avait été adopté par la plupart des critiques de M. Darwin et que des naturalistes compétents n'avaient point reculé devant ce néologisme qui nous avait semblé inutile, nous nous sommes décidés, bien qu'à regret, à l'employer, prenant sur nous d'introduire dans la langue les adjectifs sélectif et sélective,

\footnotetext{
${ }^{65}$ Primero en formular una teoría de la evolución en Philosophie zoologique ou Exposition des considérations relatives à l'histoire naturelle des animaux (1809).

${ }^{66}$ Donde elogia el triunfo de la ciencia sobre el oscurantismo, ataca las creencias religiosas y el cristianismo (ella era librepensadora, pacifista, feminista) y manifiesta posiciones eugenésicas: término posteriormente acuñado en 1883 por el primo de Darwin, Francis Galton.

${ }^{67} \mathrm{C} f$. Renouvier (1864 : 151) ; Darwin (1866: 126) et CNTRL (https://www.cnrtl.fr/etymologie/sélection).
} 
qui nous étaient indispensables, mais sans oser faire le verbe sélire qui serait élégant, mais peut-être peu compris, et encore moins le verbe sélectionner que nous craignons de voir un jour lui préférer et passer dans l'usage. En abandonnant le mot élection, que nous avions employés dans notre première édition, nous avons fait, nous l'avouons, à l'opinion du grand nombre, un sacrifice au sujet duquel, notre conscience n'est pas très tranquille. (...) Mais nous consentons à céder volontiers quelque chose sur les mots, pourvu qu'on nous permette de ne rien céder sur les idées. (Darwin, 1866: avant-propos). abiertamente:

Pero incluye íntegro el prefacio de la primera edición, donde se posiciona

La doctrine de M. Darwin, c'est la révélation rationnelle du progrès, se posant dans son antagonisme logique avec la révélation irrationnelle de la chute. Ce sont deux principes, deux religions, en lutte, une thèse et une antithèse dont je défie l'Allemand, le plus expert en évolutions logiques, de trouver la synthèse. C'est un oui et un non bien catégoriques entre lesquels il faut choisir, et quiconque se déclare pour l'un est contre l'autre. Pour moi, mon choix est fait: je crois au progrès" (Darwin, 1862: LXXI).

La tercera edición de la traducción de Clémence se publica en 1870, sin que Darwin haya estado al tanto, con un nuevo prefacio, donde critica abiertamente la pangénesis ${ }^{68}$ que Darwin había incorporado en 1868 y sin incluir las modificaciones de Darwin en las ediciones $4^{\mathrm{a}}$ y $5^{\mathrm{a}}$ en inglés, excusa que éste utiliza para romper su relación con Clémence y buscar otro traductor, en este caso varón ${ }^{69}$... Posiblemente influyó el concepto que Darwin tenía de las mujeres: «El hombre difiere de la mujer por su talla, su fuerza muscular, su vellosidad, etc., como también por su inteligencia, como sucede entre los dos sexos de muchos mamíferos» (Darwin, 2009: 8).

En 1882, año en que muere Darwin, Clémence publica una cuarta edición en Flammarion donde incluye el prefacio de la primera y un breve Avertissement

\footnotetext{
68 Teoría de Darwin para explicar la herencia (la genética no se inaugura hasta que las leyes de Mendel en 1865-1866 abren la puerta a las investigaciones sobre el ARN y el ADN a mediados del siglo XX). «Ch. Darwin, dans son hypothèse de la Pangenèse s'est laissé complètement dominer par le concept de la matière; il a négligé celui de la force. Toute théorie, qui cherchera à expliquer par une transmission de matière le phénomène de l'hérédité, tombera à faux; parce qu'il ne peut s'expliquer que par une transmission de force et de mouvement. À la Pangenèse nous opposerions donc la théorie ou, si l'on veut, l'hypothèse de Dynamogenèse si les limites de cette préface déjà trops étendue ne nous faisaient une loi d'en renvoyer autre part l'exposition» (Darwin, 1870: XXVI).

69 Jean-Jacques Moulinié, editorial, Reinwald. Esta traducción se publica en 1873 con el título L'origine des espèces au moyen de la sélection naturelle ou la lutte pour l'existence dans la nature. Posteriormente, Edmond Barbier tradujo la sexta y definitiva edición inglesa.
} 
au lecteur (4 páginas), edición que se seguirá publicando hasta 1932 sin más variaciones.

\section{Conclusiones}

Resulta interesante constatar las enormes diferencias que existen entre estas traductoras que estuvieron, a lo largo más o menos de un siglo, en el gozne de la gran revolución científica de la época y que transformó radicalmente la manera de hacer ciencia, de comunicar, compartir y divulgar ciencia.

Desde el aceptado anonimato de Madame Lavoisier o la reclamada existencia de Madame de Châtelet (in artículo mortis incluso) a la presencia con nombre y apellido (propio) de Clémence Royer, pasando por iniciales como A.A.L. o M.L. poco fáciles de identificar.

Desde la traducción sin ánimo de lucro y por iniciativa propia, por deseo de entender y explicar de Madame de Châtelet, a la traducción para satisfacer las necesidades de su marido de Madame Lavoisier o a demanda de su mentor de Ada Byron, al encargo remunerado de traducción de Mary Sommerville o de Clémence Royer.

Desde las siempre amplias aportaciones bien recibidas, agradecidas y consideradas pertinentes (a veces más esclarecedoras que el original) de Madame de Châtelet, Mary Sommerville, Ada Lovelace, pasando por la tímida discreción de Madame Lavoisier, hasta el rechazo de traductora y traducción por parte de Darwin al trabajo de Clémence Royer.

Desde la traducción al francés del latín -como única lengua científica del momento- de Madame de Châtelet, a las traducciones del inglés (cuando esta lengua empezó a ser dominante) al francés de Madame Lavoisier y Clémence Royer o las traducciones del francés al inglés de Mary Sommerville y Ada Lovelace.

Y también las similitudes.

Todas desbordaron los límites en la educación que tenían asignada por su condición de mujer y, siendo autodidactas, accedieron a un nivel de conocimiento científico transversal y multidisciplinar que les permitió realizar, demostrando la máxima competencia, traducciones de textos científicos que requerían un amplio y actualizado saber.

Todas compaginaron los roles domésticos y de esposa y madre que tenían asignados por su condición de mujer y añadieron a sus tareas el esfuerzo de realizar un trabajo (casi siempre no remunerado) para participar en la difusión de la nueva ciencia que se estaba creando. Todas fueron infatigables trabajadoras, pero ninguna fue reconocida como científica, a pesar de haber producido textos científicos. Todas padecieron, en menor o mayor medida, por su condición de mujer, silencio ocultación y/o precedencia del varón, caso de haber otras traducciones (Darwin, Laplace). Todas fueron relegadas a un papel secundario, por el hecho de ser mujeres.

Newton personalizó el cambio de paradigma reconciliando la mecánica terrestre con la mecánica celeste - cuya forma definitiva correspondió a Laplace- y enunciando las fuerzas, lo que abrió el paso a la posterior física cuántica. Lavoi- 
sier personalizó el cambio de paradigma en química resolviendo el enigma de la combustión, proponiendo una nomenclatura y enunciando la ley de conservación de la masa, lo que abrió paso a la posterior química cuántica. Darwin personalizó el cambio de paradigma en la evolución, enunciando el principio de la selección natural y de la herencia, lo que abrió paso a la posterior teoría mendeliana y la revolución genética. Pero ninguno se planteó, a pesar de que también podían haberlo observado y sacado conclusiones, cómo y por qué sus colegas mujeres, incluso de gran valía, no figuraban, no destacaban, no eran reconocidas; ninguno contribuyó al cambio de paradigma patriarcal, uno de cuyos objetivos es poner trabas al acceso de las mujeres a cualquier instancia de poder y de decisión y en este caso concreto a las ciencias, todos se prestaron a desdibujar, desvalorizar u ocultar los logros de las mujeres en ciencias, ensombreciendo y velando con su desmesurada y patriarcal presencia la de esas tenues y múltiples estrellas tan necesarias y fundamentales para avanzar en sus hallazgos y consolidarlos.

Si siguiéramos enfocando ese velo de la inmensa vía láctea para detectar estrellas y desvelarlas con todo su potencial y proyección, es posible que pudiéramos hacernos una idea más completa y cabal de la presencia y trascendencia de las mujeres en la ciencia.

Por eso, para visualizar a algunas de esas mujeres poco conocidas, ocultas o veladas, queremos finalizar recordando la tabla periódica ${ }^{70}$ de las científicas que elaboró, para conmemorar el 150 aniversario de la Tabla de Mendeléyev, la ingeniera química Teresa Valdés Solís ${ }^{71}$, situando una científica en cada elemento, organizándolas en distintas disciplinas -Ciencias Naturales, Matemáticas, Química, Ingeniería, Astronomía, Bioquímica/Biología/Medicina, Paleontologías, Física, Primatología- y reservando las tierras raras a las españolas (muy poco conocidas). Entre las matemáticas figuran Madame de Châtelet, Ada Lovelace y Mary Somerville. Y entre las químicas Marie-Anne Peulze.

Je réformerais un abus qui retranche, pour ainsi dire, la moitié du genre humain. Je ferais participer les femmes à tous les droits de l'humanité et surtout à ceux de l'esprit.

Madame de Châtelet (apud Touzery, 2006: 96).

\section{REFERENCIAS BIBLIOGRÁFICAS}

Aboites, Vicente (2001): «Los elementos de la Philosophie de Newton de Voltaire y su interpretación de la naturaleza de la luz». Revista mexicana de Física, 57:2, 134143. URL: http://www.scielo.org.mx/pdf/rmfe/v57n2/v57n2a7.pdf.

\footnotetext{
${ }^{70}$ Mendeléyev publicó la primera tabla con 63 elementos (Lavoisier, junto con Berthollet, Guyton de Morveau y el conde de Fourcroy, había identificado 33 sustancias simples, que luego quedaron reducidas a 25) Actualmente contiene 118 elementos.

${ }^{71}$ Disponible en: https://naukas.com/2018/11/23/la-tabla-periodica-de-las-cientificas.
} 
AlIC, Margaret (1991): El legado de Hipatia. Historia de las mujeres desde la Antigiëdad hasta fines del siglo XIX. Madrid, Siglo veintiuno editores.

ARÉCHIGA, Violeta (2007): Fuego y vida, fuentes del pensamiento químico de Buffon. México DF, Centro de estudios filosóficos, políticos y sociales Vicente Lombardo Toledano.

AsIMOV, Isaac (2010): Breve historia de la química. Madrid, Alianza editorial.

BADINTER, Elisabeth (1983): Émilie, Émilie. L'ambition féminine au XVIII siècle. París, Flammarion,

BADINTER, Élisabeth (2008): «Portrait de Madame du Châtelet», in Ulla Kölving \& Olivier Coucelle (coord.), Émilie du Châtelet, éclairages et documents nouveaux. París, Centre International d'études du XVIII ${ }^{\mathrm{e}}$ siècle, 13-23.

BEAUVOIR, Simone (1949): Le deuxième sexe. París, Gallimard.

BENOÎT, Paul \& Françoise MiCHEAU (1991): «Sexta bifurcación: ¿una herencia o muchas? ¿una transmisión o muchas? ¿El intermedio árabe?», in Michel Serres, Historia de la Ciencia. Madrid, Bordas, 175-201.

BENSAUDE-VINCENT, Bernardette (1991): «Décimoquinta bifurcación: ¿qué política es la ciencia? Lavoisier una revolución científica», in Michel Serres, Historia de la Ciencia. Madrid, Bordas, 411-435.

BerTOMEU, José R. \& Antonio GARCíA (2006): «La revolución química: entre la historia y la memoria». DYNAMIS, Acta Hispanica ad Medicinae Scientiarumque Historiam, 26, 307-322.

BEST, Nicholas W. (2011): «Las tablas de afinidades del siglo XVIII». Afinidades Electivas. Mètode, 69, 51-55.

Blanco, Oliva (2004): «Bajo el nombre de Darwin: Clémence Royer o la osadía intelectual». Pasajes, 14, 87-92.

BlÁzQueZ, José M. (2004): «Sinesio de Cirene, intelectual. La escuela de Hypatia en Alejandría». Gerión, 22:1, 403-419.

CÁCERES, Ingrid (2000): Relaciones internacionales, con especial referencia a las naciones y lenguas germánicas (S. XVI-XIX). Tesis doctoral. Madrid, Universidad Complutense de Madrid.

COURCELLE, Olivier (2008): «La publication tardive des Principes Mathématiques, in Ulla KÖLVING \& Olivier COUCELLE (coord.), Émilie du Châtelet, éclairages et documents nouveaux. París. Centre international d'études du XVIII ${ }^{\mathrm{e}}$ siècle, 301308.

CROMBIE Alistair Cameron (1979): Historia de la ciencia: de San Agustín a Galileo/l S. V-XIII. Madrid, Alianza Editorial.

CROMBIE Alistair Cameron (1980): Historia de la ciencia: de San Agustín a Galileo /2. Siglos XIII-XVII. Madrid, Alianza Editorial.

DARWIN,Charles (1862): De l'origine des espèces, ou des lois du progrès chez les êtres organisés. Traduction de Mme Clémence Royer avec préface et notes. París, Guillaumin et Cie, V. Masson, $1{ }^{\mathrm{e}}$ édition.

DARWIN, Charles (1870): De l'origine des espèces par sélection naturelle, ou des lois de transformation des êtres organisés. Traduction de Mme Clémence Royer avec préface et notes. París, Guillaumin et Cie, V. Masson, $3^{\mathrm{e}}$ édition. 
DARWIN,Charles (1886): De l'origine des espèces par sélection naturelle, ou des lois de transformation des êtres organisés. Traduction de Mme Clémence Royer avec préface et notes. París, Guillaumin et Cie, V. Masson, $2^{\mathrm{e}}$ édition.

DARWIN, Charles (2009 [1871] ): El origen del hombre. Traducción de Joan Domènec Ros. Barcelona, Crítica.

DeSCARTES, René (1995 [1644]): Los Principios de Filosofía. Traducción de Guillermo Quintas. Madrid Alianza Editorial.

DIDEROT, Denis \& Jean le Rond d'AlEMBerT [dir.] (1751): Encyclopédie ou Dictionnaire raisonné des arts et des métiers. París. André le Breton.

Du CHÂTELET, Gabrielle-Émilie (1961 [1779]): Discours sur le bonheur. Édition critique et commentée par Robert Mauzi. París, Société d'Édition «Les belles Lettres».

Du ChÂTELET, Gabrielle-Émilie Le Tonnelier de Breteuil (1740): Institutions de physique. París, Chez Prault fils.

Du ChÂTELET, Gabrielle-Émilie Le Tonnelier de Breteuil (1744): Dissertation sur la nature et la propagation du feu. París, Chez Prault fils.

El-MADKOURI MAATAOUI, Mohamed (2006): «Escuelas y técnicas de traducción en la Edad Media» Tonos digital. Revista electrónica de estudios filológicos, XI. URL: https://www.um.es/tonosdigital/znum11/portada/tritonos/tritonos-edadmedia.htm.

GALINDO, Salvador (2012): «Entre vórtices cartesianos y gravitación newtoniana: la Cosmología de Andrés de Guevara y Basoasabal S. J. (1748-1801)». Revista mexicana de Física, 58:2, 133-149. URL: https://rmf.smf.mx/ojs/rmfe/article/view/4689/4595.

GARDINER, Linda (2008): «Mme du Châtelet traductrice», in Ulla Kölving, y Olivier Coucelle (coord.): Émilie du Châtelet, éclairages et documents nouveaux. París, Centre International d'études du XVIII' siècle, 167-172.

GEBELEIN, Helmut (2007): Secretos de la alquimia. Barcelona, Ediciones Robinbook.

GÓMEZ, Francisco J. (1998): Pierre Simon de Laplace. URL: https://thales.cica.es/rd/Recursos/rd97/Biografias/09-01-b-LaplaceIndice.htm.

HAWKING, Stephen (2006): Brevísima historia del tiempo. Barcelona, Crítica.

HERMANN, Claudine (2008): «La traduction et les commentaires des Principia de Newton par Émilie du Châtelet». Bibnum. URL: http://journals.openedition.org/bibnum/722.

KAWASHIMA Keiko (2000): «Madame Lavoisier et la traduction française de l'Essay on phlogiston de Kirwan». Revue d'histoire des sciences, 53:2, 235-264

KIRWAN, Richard (1788): Essai sur le Phlogistique, et Sur la Constitution des Acides, Traduit de l'Anglois de M. Kirwan; Avec des Notes de MM. de Morveau, Lavoisier, de la Place, Monge, Berthollet, \& de Fourcroy. París, Rue et hotel Serpente.

KÖLVING Ulla \& Olivier COUCELLE [coord.] (2008): Émilie du Châtelet, éclairages et documents nouveaux. París, Centre international d'études du XVIII ${ }^{\mathrm{e}}$ siècle.

KuHN, Thomas Samuel (1971): La estructura de las revoluciones científicas. México. Fondo de Cultura Económica. 
LAFORTUNE, Louise (1986): Femmes et mathématiques. Montréal, Les éditions du remue-ménage.

LAPLACE, Pierre-Simon (1796): Exposition du système du monde. París, Imprimerie du cercle social.

LAPLACE, Pierre-Simon (1798-1824): Traité de mécanique céleste. París, Duprat.

LAPLACE, Pierre-Simon (1840): Essai philosophique sur les probabilités. París, Bachelier.

LAVOISIER, Antoine (1789): Traité élementaire de chimie présenté dans un ordre nouveau et d'après les découvertes modernes. París, Cuchet.

Lavoisier, Antoine [avec L. B. GuYton de Morveau, C. Berthollet \&A.F. FOURCROY] (1878): Méthode de nomemclature chimique. París, Cuchet.

LECAILLE, Claude (1994): «El Flogisto. Ascenso y caída de la primera gran teoría química». Ciencias, 34, 4-10.

LOCQUENEUX, Robert (1995): «Les Institutions de physique de Madame du Chatelet ou d'un traité de paix entre Descartes, Leibniz et Newton». Revue du Nord, 77:312, 859-892.

MACARRÓN MACHADO, Ángeles (2009): «Madame du Châtelet, leibniziana malgré Voltaire». Thémata. Revista de filosofía, 42, 51-75.

MAIRAN, Jean-Jacques (1741): Lettre de M. de Mairan,... à Madame *** [la marquise du Chatelet] sur la question des forces vives, en réponse aux objections qu'elle lui fait sur ce sujet dans ses «Institutions de physique». URL: https://gallica.bnf.fr/ark:/12148/bpt6k73081z.pdf.

MASON, Stephen F. (1995): Historia de las ciencias, 2: La revolución científica de los siglos XVI y XVII. Madrid, Alianza Editorial.

Molero, María \& Adela SAlvador (2003): Mme. de Chatelet. Madrid, Ed. Orto

NAEGELE, Daniel (2007): «La puertas y ventanas de Duchamp: Fresh widow, Bagarre d'Austerlitz, Puerta: 11 rue Larrey, la puerta Gradiva, Étant donnés». Revista de arquitectura, 9, 43-60.

NEWTON, Isaac (2011 [1687]): Principios matemáticos de la filosofía natural. Traducción de Eloy Rada. Madrid, Alianza Editorial.

NEWTON, Isaac (1759): Principes mathématiques de la philosophie naturelle, par feue Madame la Marquise du Chastellet. Paris, Dessaint \& Saillant et Lambert, Imprimeurs.

PÉREZ, Joaquín \& Ignacio M. PASCUAL (2010): «Sobre la relación entre la mujer y la alquimia: del laboratorio al símbolo». Dossiers feministes, 14, 34-54.

PETIT, Jérôme (2010): «La traduction française de L'Origine des espèces». Le Blog Gallica URL: https://gallica.bnf.fr/blog/01012013/la-traduction-francaise-delorigine-des-especes.

PoINCARÉ, Henri (1906): «La Voie lactée et la théorie des gaz». Bulletin de la Société astronomique de France, 20, 153-165.

PRIETO, María José (2017): Pensar la ciencia desde la biología. Barcelona, Universitat de Barcelona Edicions. 
RENOUVIER, Charles (1864): Essais de Critique Générale. $3^{\mathrm{e}}$ essai. París, Librairie philosophique de Ladrange.

RuELLAND, Jacques (2004): «Marie-Anne Pierrette Paulze-Lavoisier, comtesse de Rumford (1758-1836): Lumière surgie de l'ombre». Dix-huitième siècle, 36, 99-112.

SÁNCHEZ-CEREZO DE LA FuENTE, José (2003): «Thomas Samuel Kuhn (1922-1996)». Webdianoia. URL: https://www.webdianoia.com/contemporanea/kuhn.htm.

SMARTT, Madison (2013): Lavoisier en el año uno de la revolución. Barcelona, Antoni Bosch Editor.

STENGERS, Isabelle (1991): «Novena bifurcación: ¿Un proceso a Galileo o varios? Los episodios galileanos», in Michel Serres, Historia de la Ciencia. Madrid, Bordas, 255-285.

TOUZERY, Mireille (2008): «Émilie Du Châtelet, un passeur scientifique au XVIII ${ }^{\mathrm{e}}$ siècle». La revue pour l'histoire $d u$ CNRS, 21.URL: https://doi.org/10.4000/histoire-cnrs.7752.

TOUZERY, Mireille \& Geneviève MENANT (2006) Catalogue de l'exposition Émilie du Châtelet 1706-1749. Une femme de sciences et de lettres à Créteil. URL: http://www.univ-paris12.fr/ bibliothèques/expositions.

Troitiño, M. Dolores; M. Ángeles DE LA PlaZA; M. Cruz IZQUIERdo y Fernando PERAL (2007): «Las mujeres y la ciencia: El singular destino de Marie Anne Paulze, Mme Lavoisier de Rumford».100cias@uned, 10, 109-116.

VALDÉS, Teresa (2018): «Tabla periódica de las científicas». Naukas. [Consulta en línea: https://naukas.com/2018/11/23/la-tabla-periodica-de-las-cientificas.

VOLTAIRE (1879 [1738]): «Épître dédicatoire de l'auteur à Mme du Châtelet», in Éléments de la philosophie de Newton. Euvres complètes. París, Garnier, vol. 22, 400.

Voltaire (1879 [1734]): Lettres philosophiques. Euvres complètes. París. Garnier, vol. 22.

Voltaire (1975): Correspondance. París, Gallimard («Bibliothèque de la Pléiade»), t. III.

WURTZ, Adolphe (1869-1908): Dictionnaire de chimie pure et appliquée. París. Hachette 